\title{
EFFECT OF VITAMIN C ON BISPHENOL A INDUCED HEPATO\& NEPHROTOXICITY IN ALBINO RATS
}

\author{
Marcelle R. Haroun,M.D.", Ibrahim S. Zamzam, M.D. ",Eslam S. Metwally, M.D.., and \\ Rabab Sh. EL-Shafey, M.S.C. \\ *Forensic Medicine \& Clinical Toxicology Department, Faculty of Medicine, Benha \\ University, Egypt \\ marcel.haroun@fmed.bu.edu.eg \\ ibrahim.zamzam@fmed.bu.edu.eg \\ islam.mitwalli@fmed.bu.edu.eg \\ rabab.mohamed@fmed.bu.edu.eg
}

\begin{abstract}
Bisphenol-A (BPA) is a worldwide used endocrine disruptor that is incorporated in many plastic industries. The exposure of humans to that substance starts early during the fetal life. Many agencies raised warnings against the excessive use of such substances. The present study aimed to evaluate the oxidative stress effect of BPA on liver and kidney of albino rats, and whether co-administration of vitamin $\mathrm{C}$ can ameliorate this oxidative damage. Albino rats were divided into six groups: -ve control group,+ve control group,vitamin C $(60 \mathrm{mglkg})$ treated group, BPA treated group, BPA+ high dose of vitamin $\mathrm{C}(60 \mathrm{mglkg})$ treated group, and BPA+ low dose of vitamin $\mathrm{C}(5.5 \mathrm{mglkg})$ treated group The oxidative stress arising from BPA was evaluated in liver and kidney tissues. In addition, serum creatinine, uric acid levels, (AST) and (ALT) activities as markers of kidney and liver function were measured. Biochemical analysis revealed significant reduction in activities of enzymatic antioxidants in BPA treated group and BPA + vitamin C treated groups in high \& low doses as compared to control group. In addition, there were significant increase in AST, ALT, uric acid, and creatinine levels in BPA treated group and reduction in their concentrations $\mathrm{BPA}+$ vitamin $\mathrm{C}$ treated groups in high \& low doses as compared to control group. Histopathological and ultrastructure changes of liver and kidney were observed in BPA treated group and BPA + vitamin C treated groups as compared to control group. The present study demonstrated that BPA could induce hepato\& nephrotoxicity, affecting oxidant/antioxidant balance in rat liver and kidney. In addition, Co-administration of vitamin $\mathrm{C}$ in low dose $(5.5 \mathrm{mg} / \mathrm{kg})$ didn't prevent this oxidative damage. While co-administration of vitamin $C$ in high dose $(60 \mathrm{mg} / \mathrm{kg})$ augmented this oxidative damage.
\end{abstract}

Keywords: Bisphenol A, Vitamin C, Oxidative stress, andantioxidants.

\section{INTRODUCTION}

BPA is an endocrine disrupting chemical which is used mainly as a monomer in the production of polycarbonate plastics (PC) and as a precursor of epoxy resins. Polycarbonate plastics are used in food and drink containers, the resins are used as lacquers to coat metal products such as food cans, bottle tops, and water supply pipes. In addition, BPA is used in the production of other types of resins, flame-retardants, and in the processing of polyvinyl chloride plastic and in the manufacturing of thermal paper. Some polymers used in dental 
sealant and tooth coatings contain BPA as listed in reports of the European Commission's former European Chemicals Bureau (ECB, 2008). The ubiquitous and extensive use of BPA containing products results in a high human exposure worldwide (Vandenberg et al., 2010) .

the primary endocrine disrupting activities of BPA extend beyond its ability to mimic, enhance or inhibit the activity of endogenous estrogens and/or disrupt estrogen nuclear hormone receptor action, and include effects upon the androgen systems (Sun et al., 2006), disruption of thyroid hormone function (Hamers et al., 2006), diverse influences on development, differentiation and function of the central nervous system (Miyatake et al., 2006), and influences on the immune system (Tian et al., 2003).

BPA can cause liver, kidneys, brain, and other organs injury by formingreactive oxygen species (ROS). Reactive oxygen species are cytotoxic agents causing oxidative damage by attacking cell membrane and DNA. Antioxidants are scavengers by preventing cell and tissue damage that could lead to diseases (Kabuto et al., 2004).

Vitamin $\mathrm{C}$ is an important dietary antioxidant which significantly decreases the adverse effects of ROS formed in the cell. Many biochemicals, clinical and epidemiologic studies have indicated that vitamin $\mathrm{C}$ may be of benefit in chronic diseases such as cardiovascular disease, cancer, and cataract, probably through antioxidant mechanisms (Carr and Frei, 1999).

Antioxidants neutralize ROS by donating one of their own electrons, ending the electron "stealing" reaction; they act as scavengers, helping to prevent cell and tissue damage that could lead to diseases (Halliwell, 1999). But, with the excessive production of ROS for any reason, the oxidative damage occurs in the cells. Also, many environmental contaminants have been reported to disrupt the prooxidant/antioxidant balance of cells by inducing oxidative stress (Ho et al., 1998).

The majority of studies on BPA have focused on its endocrine disrupting and potential adverse effects on the developing reproductive system. However, there is only limited information concerning the effects of it on other tissues, so that the present study aimed to evaluate the oxidative stress effect of BPA on liver and kidney and whether co-administration of vitamin $\mathrm{C}$ can ameliorate this oxidative damage in albino rats.

\section{MATERIAL \& METHODS}

\section{Chemicals used}

BisphenolA (BPA) powder (97\%) purity was purchased from SigmaAldrich Company (USA).

Vitamin C powder (100\%) purity was purchased from ELGomhureia pharmaceutical and chemicalcompany, Cairo, Egypt.

\section{Design}

Animals and Experimental

Experimental Animals: Seventy two adult albino rats weighing 180-200 $\mathrm{g}$ were maintained on stock diet and kept under fixed appropriate conditions of housing and handling. All experiments were carried out in accordance with the research protocols according to the Ethics Committee of Scientific Research, Faculty of Medicine, Banha University which followed the recommendations of the National Institutes of Health Guide for 
Care and Use of Laboratory Animals (Publication No. 85-23, revised 1985).

The albino rat was the animal of choice for the experiments. This is because the anatomy as well as physiology of these animals is closely related to that of human and most of chemical and biochemical experimental studies were carried out with these animals often produce similar results with those conducted on human (Ogunleye and Omotoso, 2005).

Experimental Design: The animals were equally divided into six groups:-

(1) Group I (negative control group): lifted without intervention to measure the basic parameters.

(2) Group II (positive control group): Each rat was treated with olive oil (vehicle of bisphenol A \& vitamin C) once daily, orally for six weeks.

(3) Group III (vitamin C treated group): each rat was treated with vitamin $\mathrm{C} \quad(60 \mathrm{mg} / \mathrm{kg} /$ day $)$ dissolved in olive oil, once daily, orally, for six weeks.

(4) Group IV (bisphenol A treated group): Each rat was treated with bisphenol A $(25 \mathrm{mg} / \mathrm{kg} /$ day $)$ dissolved in olive oil, once daily, orally, for six weeks.

(5) Group V (treated with bisphenol $A$ and high dose of vitamin C): Each rat was treated orally with bisphenol A (25 mg/kg/ day) and vitamin C (60 mg $/ \mathrm{kg} /$ day) once daily, orally, for six weeks.

(6) Group VI (treated with bisphenol $A$ and low dose of vitamin C): Each rat was treated orally with bisphenol A (25 mg/kg/ day) and vitamin C (5.5 mg $/ \mathrm{kg} /$ day). This dose of vitamin $\mathrm{C}$ was calculated by extrapolating the therapeutic dose to rat dose on the basis of body surface area ratio (conversion factor 0.018 for rats) by referring to the table of "Paget $\&$ Barnes" (Paget and Barnes, 1964). i.e. For rats, Humans dose x $0.018=\mathrm{X}$ $\mathrm{g} / 200 \mathrm{gm}$ of rat. So rat dose $=1.08$ $\mathrm{mg} / 200 \mathrm{gm}$ of rat/ day. Conversion to dose $/ \mathrm{kg}$ body wt. $=1.08 \mathrm{mg} \times 5=$ $5.4 \mathrm{mg} / \mathrm{kg}$ (nearly about $5.5 \mathrm{mg} / \mathrm{kg}$ ).

The selection of these doses was based on the previous study done by Korkmaz et al., (2010).

All animals were received the drugs orally. The oral administration was via appropriate sized metallic cannula dressed with plastic cover that exceeds the tip by $2-3 \mathrm{~mm}$ to prevent injury of the esophagus.

At the end of the experiment the animals were sacrificed and subjected to the following.

\section{A) Biochemical study:}

\section{Preparation of serum:}

Blood samples were taken from their hearts by $5 \mathrm{ml}$ syringes. Blood samples were left to coagulate at room temperature, then centrifuged at $986 \mathrm{~g}$ for 15 minutes, the clear nonhemolyzed supernatant serum was quickly removed and used for the estimation of serum enzymes (AST, ALT), uric acid and creatinine.

\section{Handling of tissue samples:}

The liver and kidney of each animal was quickly removed, weighed and handled as following:-

1- A portion of both organs was dissected and rapidly frozen until analyzed. The liver is homogenized in $10 \mathrm{ml}$ and kidney in $6 \mathrm{ml}$ of ice cold phosphate buffer $(50 \mathrm{mM} \mathrm{pH} \mathrm{7.4,} \mathrm{0.1 \%}$ triton $\mathrm{X}$ and $0.5 \mathrm{mM}$ EDTA). The homogenates were centrifuged at 1753 $\mathrm{g}$ for $15 \mathrm{~min}$ at $4^{\circ} \mathrm{C}$ using a high speed cooling centrifuge (Type 3K-30, 
Sigma, Osterode-am-Harz, Germany). The clear supernatants were separated and used for analysis of oxidative stress parameters.

2- Another portion of both organs was dissected and settled in $10 \%$ formalin for histopathological examination.

3- The rest of both organs were settled in $4 \%$ glutaraldehye for electron microscopic examination.

\section{- Oxidative stress parameters assessment:}

\section{Lipid peroxidation}

Lipid peroxidation was assayed by determining the level of malondialdehyde (MDA) by measuring thiobarbituric reactive species using the method of Chattopadhyay et al.,(2003). The thiobarbituric acid reactive substances react with thiobarbituric acid to produce a pink colored complex, which can be read colorimetriclly at $532 \mathrm{~nm}$.

\section{- Assay of antioxidant enzymes}

1- Superoxide dismutase (SOD);-

SOD was assayed according to the method of Kakkar et al. (1984). The assay of SOD is based on the inhibition of formation of NADHphenazinemethosulfate nitrobluetetrazoliumformazon. The colour formed at the end of the reaction can be extracted into butanol and measured at 560 $\mathrm{nm}$.

\section{2- Catalase (CAT):}

Catalase activity was assayed by measuring the breakdown of hydrogen peroxide $\left(\mathrm{H}_{2} \mathrm{O}_{2}\right)$. The weighed amounts of the hepatic tissue were homogenized in 5\% ice-cold $50 \mathrm{mM}$ phosphate buffer $\mathrm{pH}$ 7.2. The homogenates were then centrifuged at $12000 \times \mathrm{g}$ for $12 \mathrm{~min}$. The supernatantthus obtained was then carefully collected and incubated with $0.01 \mathrm{ml}$ of absolute ethanol at $4^{\circ} \mathrm{C}$ for
30 min. Thereafter, $10 \%$ Triton $\mathrm{X}-100$ was added to have a final concentration of $1 \%$. The sample, thus obtained, was used to determine the catalase activity by measuring the breakdown of $\mathrm{H}_{2} \mathrm{O}_{2}$ spectrophotometrically at $240 \mathrm{~nm}$ (Mukherjee et al., 2010)

\section{3- Glutathione peroxidase (GPX) :}

The method proposed by Reddy et al. (1995) was adopted for assaying the activity of peroxidase. In the presence of hydrogen donor pyrogallol or dianisidine, peroxidase converts $\mathrm{H}_{2} \mathrm{O}_{2}$ to $\mathrm{H}_{2} \mathrm{O}$ and $\mathrm{O}_{2}$. The oxidation of pyrogallol or dianisidine to a coloured product called purpurogalli can be followed spectrophotometrically at 430nm.

\section{- Assay of liver enzymes}

\section{1- Alanine aminotransferase}

(ALT):-

Glutamate pyruvate transaminase (GPT) level was calculated spectrophotometrically using the commercial test of GPT (ALT) with spin lab (Spinreact company), Spain.

\section{2- Aspartate aminotransferase (AST):- \\ Glutamate oxaloacetate} transaminase (GOT) level was calculated spectrophotometrically using the commercial test of GOT (AST) with spin lab (Spinreact company), Spain.

\section{- Assay of renal functions}

\section{1- Creatinine:-}

Creatinie level was calculated spectrophotometrically using the commercial test of CREATINIE-J with spin lab (Spinreact company), Spain

\section{2- Uric acid:-}

Uric acid level was calculated spectrophotometrically using the commercial test of URIC ACID-LQ with spin lab (Spinreact company), Spain. 
- The diagnosis of higher or lower values of the previous parameters depends on on the mean value plus or minus standared deviation of rats of control group. :

\section{B) Histological staining}

Autopsy samples taken from the liver and kidney of rats in different groupswere processed according to Lamberg and Rothstein (1978), stained with Haematoxylin and Eosin $(\mathrm{H} \& \mathrm{E})$, and examined at pathology department in Benha faculty of medicine.

\section{C) Electron microscope study:}

Autopsy samples taken from the liver and kidney of rats in different groups were processed according to Maunsbach and Afzelius (1999), and examined by transmission electron microscope at 80 kilo volts. Photographs were taken, developed, examined and printed at electron microscope unit in Tanta University.

\section{Statistical analysis}

The clinical data were recorded on a report form. These data were tabulated and analyzed using the computer program SPSS (Statistical package for social science) version 16 to obtain:

\section{Descriptive data}

Descriptive statistics were calculated for the data in the form of mean and standard deviation $( \pm S D)$. for quantitative data.

\section{Analytical statistics}

In the statistical comparison between the different groups, the significance of difference was tested using ANOVA test ( $F$ value) that used to compare mean of more than two groups of quantitative data. A $\mathrm{P}$ value $<0.05$ was considered statistically significant (S) while $\mathrm{P}>0.05$ was considered statistically insignificant, $\mathrm{P}$ value $<0.01$ was considered highly significant (HS) in all analyses.

\section{RESULTS}

\section{1- Biochemical study:}

\section{1- As regard the control groups:}

Group I (-ve control), group II (+ve control group), and group III (vitamin $\mathrm{C}$ treated group). There was a nonsignificant difference $(\mathrm{p}>0.05)$ between groups all over the period of the study by ANOVA test as regard:

1-ALT, AST and hepatic MDA (table 1).

2- SOD, GPX, and catalase activity in hepatic tissue (table 1).

3- Uric acid, creatinine, and renal MDA (tables 2).

4- SOD, GPX, and catalase activity in renal tissue (table 2).

So the negative control group was chosen as a representative group to be compared with the results of the treated groups; [group IV (bisphenol A treated group), group $\mathrm{V}$ (bisphenol $\mathrm{A}+$ high dose of vitamin $\mathrm{C}$ treated group), and group VI (bisphenol A + low dose of vitamin $\mathrm{C}$ treated group)].

2- As regard treated group:

1) Comparison between studied groups (I,IV,V,VI) regarding liver enzymes (AST, ALT):-

The present study showed a significant increase in ALT \& AST levels in group IV (BPA treated group) group V (BPA + high dose of vitamin $C$ treated group) \& non significant increase in their levels in group VI (BPA + LOW dose of vitamin C treated group, as compared to group I (-ve control group). but there was a reduction in AST \& ALT levels in groups V, VI as compared to group IV which was significant for AST only (Table 3). 
2) Comparison between the studied groups (I,IV,V,VI) regarding renal functions:-

The present study showed an increase in uric acid \& creatinine levels in groups IV , $\mathrm{V} \&$ an increase in creatinine with decreased uric acid concentrations in group VI as compared to group I. but there was a significant reduction in their concentrations in groups $\mathrm{V} \& \mathrm{VI}$ as compared to group IV (BPA treated group) (Table 3).

3) Comparison between the studied groups (I,IV,V,VI) regarding liver MDA (a marker of lipid peroxidation):-

The present study showed an increased level of MDA production in group IV (BPA treated group), group V (BPA + high dose of vitamin C treated group), and group VI (BPA + low dose of vitamin $\mathrm{C}$ treated group) as compared to group I (-ve control group), also, there was a significantly increased level of MDA production in group V (BPA + high dose of vitamin $\mathrm{C}$ treated group) \& group VI (BPA + low dose of vitamin $C$ treated group) as compared to group IV (BPA treated group) (Table 3).

4) Comparison between the studied groups (I,IV,V,VI) regarding liver antioxidants:-

The present study showed that the liver CAT, SOD, and, GPX concentrations in groups IV, V \& VI were significantly lower than group. Furthermore, there were significant reduction in their concentrations in (BPA + high dose of vitamin C) treated group as compared to BPA treated group. But, there was a non significant reduction in CAT \& a non significant increase in SOD and GPX concentrations in group VI (BPA + low dose of vitamin C) treated group as compared to group IV (BPA group) (Table 3).

5) Comparison between the studied groups $(I, I V, V, V I)$ regarding kidney MDA :-

The present study showed an increased level of MDA production in kidney in groups IV, $\mathrm{V} \& \mathrm{VI}$ as compared to group I. The increased MDA in grou (BPA +high dose of vit c) p V was statistically significant as compared to group IV. But, there was a non significant reduction in its concentration in group VI (BPA + low dose of vit c) as compared to group IV (BPA treated group) (Table 3).

6) Comparison between the studied groups (I,IV,V,VI) regarding kidney antioxidants:-

The present study showed that kidney CAT, SOD, and GPX concentrations in groups IV, V \& VI were significantly lower than group I. Furthermore, there were significant reduction in their concentrations in (BPA + high dose of vitamin C) treated group as compared to BPA treated group. But, also there was a nonsignificant increase in CAT, SOD, and GPX concentrations in group VI (BPA + low dose of vitamin C) as compared to group IV (BPA treated group) (Table 3).

\section{2 - Histopathological results}

The Liver Tissue: In control groups \& vitamin $C$ treated group, Light microscopic examination of sections from the liver of these groups showed the same structures, the normal histological picture of the liver was recorded. The liver sections revealed normal hepatic plates radiating from a thin walled central vein (arrow1) separated by blood sinusoids and polyhedral hepatocytes contained 
rounded vesicular nuclei (Fig. 1). In BPA treated group, disarrangement of hepatic plates, dilatation and congestion of blood sinusoids and congested dilated central vein as shown in (Fig. 2), swollen hepatocytes with severe vacuolar (hydropic) degeneration as shown in (Fig. 3), Moreover, marked inflammatory cellular infiltrations were noticed in the portal area as shown in (Fig. 4). In BPA + vitamin C treated groups in high \& low doses, the same histopathological disruption were seen in both groups of BPA + vitamin C in high \& low doses. There was a hydropic degeneration of hepatocytes, dilated blood sinusoids and inflammatory cell infiltration in interstitial tissue and in portal tracts as shown in (Fig. 5, 6, 7 respectively).

The Renal Tissue: In control groups \& vitamin $C$ treated group, light microscopic examination of sections from the kidney showed normal histological picture of renal corpuscles and tubules were recorded. The renal corpuscle contained tuft of blood capillaries, glomerulus, surrounded by two layers of Bowman's capsule that separated by urinary space. The renal tubules consisted of proximal convoluteed tubules lined with large pyramidal cells with apical brush borders, while the distal convoluted tubules lined with simple cuboidal cells (Fig. 8). The bisphenol A treated group showed degenerative changes in the renal corpuscles and tubules, atrophied renal corpuscles with contracted glomerular tufts and widening of the urinary space. Degeneration of renal tubular epithelium with luminal dilatation was detected as shown in (Fig. 9). In groups treated with BPA + vitamin C in high \& low doses, the same histopathological disruptions were seen in both groups. Degeneration of renal tubular epithelium with luminal dilatation, and atrophied renal corpuscles are shown in (Fig. 10, 11, 12 respectively).

\section{3-Electron microscopic results}

The Liver Tissue: In control groups \& vitamin $\mathrm{C}$ treated group, the results revealed normal hepatocytes ultrastructure including mitochondria, rough endoplasmic reticulum, and nucleus as shown in (fig. 13), while BPA treated group, showed mitochondrial swelling as shown in (Fig. 14), and lipid accumulation in the liver cells as shown in(Fig. 15). Also, rats treated with BPA and vitamin C in high $\&$ low doses showed mitochondrial swelling and lipid accumulation in the liver cells as shown in (Fig. 16, 17).

The Renal Tissue: Control groups \& vitamin $C$ treated group, there was normal podocytes with normal foot processes as shown in (Fig. 18). While BPA treated group showed enlargement of foot processes of podocytes, and thickening of basement membrane of Bowman's capsule as shown in (Fig. 19). Renal tissue in rats treated with BPA and vitamin $\mathrm{C}$ in high \& low doses revealed also enlargement of foot processes of podocytesas shown in (Fig. 20, 21). Figures for the negative control group were representative for other control group \& vitamin $\mathrm{C}$ treated group. 
Table (1): Comparison between studied groups [group 1 (-ve control group), group II (+ve control group treated with the vehicle), and group III (treated with vitamin C $60 \mathrm{mg} / \mathrm{kg}$ )] regarding hepatic parameters (ALT, AST, MDA. CAT, SOD \& GPX)

\begin{tabular}{|l|l|l|l|l|l|}
\hline & $\begin{array}{l}\text { Group I (-ve } \\
\text { Control group) } \\
\text { Mean + SD }\end{array}$ & $\begin{array}{l}\text { Group II (+ve } \\
\text { Control group) } \\
\text { Mean } \pm \text { SD }\end{array}$ & $\begin{array}{l}\text { Group III (Vit } \\
\text { C ttt group) } \\
\text { Mean } \pm \text { SD }\end{array}$ & ANOVA & $\begin{array}{l}\text { P } \\
\text { value }\end{array}$ \\
\hline ALT & $83.12 \pm 11.24$ & $78.1 \pm 10.78$ & $78.76 \pm 11.71$ & 0.60 & 0.55 \\
\hline AST & $151.96 \pm 12.0$ & $152.88 \pm 13.67$ & $147.09 \pm 10.71$ & 0.66 & 0.52 \\
\hline MDA & $52.74 \pm 17.92$ & $39.19 \pm 11.74$ & $44.93 \pm 17.3$ & 1.94 & 0.16 \\
\hline CAT & $76.62 \pm 4.71$ & $75.2 \pm 9.72$ & $71.99 \pm 8.57$ & 0.88 & 0.43 \\
\hline SOD & $52.53 \pm 8.36$ & $54.28 \pm 7.38$ & $56.64 \pm 4.20$ & 0.90 & 0.42 \\
\hline GPX & $32.92 \pm 4.26$ & $33.08 \pm 3.77$ & $31.97 \pm 4.05$ & 0.23 & 0.80 \\
\hline
\end{tabular}

Table (2): Comparison between studied groups [group 1 (-ve control group), group II (+ve control group treated with the vehicle), and group III (treated with vitamin C $60 \mathrm{mg} / \mathrm{kg}$ )] regarding renal parameters (creatinine, uric acid, MDA, CAT, GPX \& SOD).

\begin{tabular}{|c|c|c|c|c|c|}
\hline & $\begin{array}{c}\text { Group I (-ve } \\
\text { Control group) } \\
\text { Mean + SD }\end{array}$ & $\begin{array}{c}\text { Group II (+ve } \\
\text { Control group) } \\
\text { Mean + SD }\end{array}$ & $\begin{array}{c}\text { Group III (Vit } \\
\text { C ttt group) } \\
\text { Mean } \pm \text { SD }\end{array}$ & ANOVA & $\begin{array}{c}\text { P } \\
\text { value }\end{array}$ \\
\hline Creatinine & $0.598 \pm 0.35$ & $0.663 \pm 0.12$ & $0.752 \pm 0.27$ & 0.89 & 0.42 \\
\hline Uric acid & $1.72 \pm 0.21$ & $1.87 \pm 0.24$ & $1.81 \pm 0.30$ & 0.96 & 0.40 \\
\hline MDA & $56.54 \pm 15.96$ & $44.53 \pm 11.51$ & $47.19 \pm 13.74$ & 2.16 & 0.14 \\
\hline CAT & $65.09 \pm 4.59$ & $53.44 \pm 22.4 €$ & $59.2 \pm 10.82$ & 1.59 & 0.22 \\
\hline GPX & $28.78 \pm 2.42$ & $30.02 \pm 2.16$ & $30.35 \pm 2.3$ & 1.32 & 0.28 \\
\hline SOD & $56.63 \pm 5.43$ & $52.0 \pm 12.01$ & $55.43 \pm 11.83$ & 0.58 & 0.57 \\
\hline
\end{tabular}


Table (3) Comparison between the studied groups regarding liver enzymes, renal functions, and oxidative stress parameters

\begin{tabular}{|c|c|c|c|c|c|c|}
\hline & 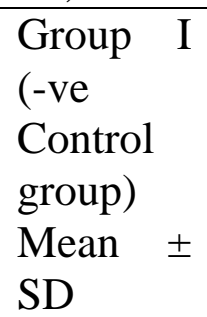 & $\begin{array}{l}\text { Group IV } \\
\text { (group } \\
\text { with BPA) } \\
\text { Mean } \pm \text { SD }\end{array}$ & $\begin{array}{l}\text { Group } \mathrm{V} \\
\text { (group ttt with } \\
\text { BPA+high } \\
\text { dose vit C) } \\
\text { Mean } \pm \text { SD }\end{array}$ & $\begin{array}{ll}\begin{array}{l}\text { Group } \\
\text { (group }\end{array} & \mathrm{VI} \\
\text { with } \\
\text { BPA+low } \\
\text { dose vit C) } \\
\text { Mean } \pm \text { SD }\end{array}$ & $\begin{array}{l}\text { ANO } \\
\text { VA }\end{array}$ & $\begin{array}{l}\mathrm{P} \\
\text { value }\end{array}$ \\
\hline ALT & $\begin{array}{l}83.12 \pm 11 \\
.24\end{array}$ & $\begin{array}{l}103.67 \pm 23.79 \\
€ \infty^{\wedge}\end{array}$ & $96.0 \pm 15.650^{\wedge}$ & $92.25 \pm 23.19$ & 3.61 & $\begin{array}{l}0.007 \\
* *\end{array}$ \\
\hline AST & $\begin{array}{l}151.96 \pm 1 \\
2.0\end{array}$ & $\begin{array}{l}213.8 \pm 17.24 € \\
\infty^{\wedge}\end{array}$ & $\begin{array}{l}187.96 \pm 43.06 \\
€^{\wedge} \$\end{array}$ & $\begin{array}{l}162.31 \pm 32.27 \\
\$ \#\end{array}$ & 11.45 & $\begin{array}{l}0.001 \\
* *\end{array}$ \\
\hline MDA & $\begin{array}{l}52.74 \pm 17 \\
.92\end{array}$ & $\begin{array}{l}62.76 \pm 23.74 \\
\infty\end{array}$ & $\begin{array}{l}133.85 \pm 36.36 \\
€ \infty^{\wedge} \$\end{array}$ & $66.6 \pm 46.31 \$ \#$ & 13.2 & $\begin{array}{l}0.001 \\
* *\end{array}$ \\
\hline CAT & $\begin{array}{l}76.62 \pm 4 . \\
71\end{array}$ & $\begin{array}{l}51.76 \pm 9.29 € \\
\infty^{\wedge}\end{array}$ & $\begin{array}{l}33.79 \pm 10.49 \\
€ \infty^{\wedge} \$\end{array}$ & $\begin{array}{l}49.68 \pm 9.85 € \\
\infty^{\wedge} \#\end{array}$ & 34.77 & $\begin{array}{l}0.001 \\
* *\end{array}$ \\
\hline SOD & $\begin{array}{l}52.53 \pm 8 . \\
36\end{array}$ & $\begin{array}{l}33.25 \pm 9.63 € \\
\infty^{\wedge}\end{array}$ & $\begin{array}{l}16.08 \pm 5.71 € \infty \\
\wedge \$\end{array}$ & $\begin{array}{l}34.31 \pm 10.23 € \\
\infty^{\wedge} \#\end{array}$ & 37.07 & $\begin{array}{l}0.001 \\
* *\end{array}$ \\
\hline GPX & $\begin{array}{l}32.92 \pm 4 . \\
26\end{array}$ & $\begin{array}{l}22.93 \pm 4.09 € \\
\infty^{\wedge}\end{array}$ & $\begin{array}{l}14.89 \pm 5.29 € \infty \infty \\
\wedge \$\end{array}$ & $\begin{array}{l}28.95 \pm 11.94 \$ \\
\#\end{array}$ & 11.57 & $\begin{array}{l}0.001 \\
* *\end{array}$ \\
\hline $\begin{array}{l}\text { Creatin } \\
\text { ine }\end{array}$ & $\begin{array}{l}0.598 \pm 0 . \\
35\end{array}$ & $\begin{array}{l}0.968 \pm 0.23 € \\
\infty\end{array}$ & $0.761 \pm 0.135$ & $0.66 \pm 0.18 \$$ & 3.01 & $\begin{array}{l}0.019 \\
*\end{array}$ \\
\hline $\begin{array}{l}\text { Uric } \\
\text { acid }\end{array}$ & $\begin{array}{l}1.72 \pm 0.2 \\
1\end{array}$ & $\begin{array}{l}2.53 \pm 0.56 € \infty \\
\wedge\end{array}$ & $1.93 \pm 0.35 \$$ & $1.29 \pm 0.75 \$$ & 7.66 & $\begin{array}{l}0.001 \\
* *\end{array}$ \\
\hline MDA & $\begin{array}{l}56.54 \pm 15 \\
.96\end{array}$ & $\begin{array}{l}69.5 \pm 27.11 \infty \\
\wedge\end{array}$ & $\begin{array}{l}97.8 \pm 33.66 € \infty \\
\wedge \$\end{array}$ & $\begin{array}{l}68.12 \pm 23.8 \infty 0 \\
\wedge \#\end{array}$ & 7.29 & $\begin{array}{l}0.001 \\
* *\end{array}$ \\
\hline CAT & $\begin{array}{l}65.09 \pm 4 . \\
59\end{array}$ & $\begin{array}{l}30.31 \pm 8.24 € \\
\infty^{\wedge}\end{array}$ & $\begin{array}{l}33.0 \pm 15.02 € \infty \\
\wedge\end{array}$ & $\begin{array}{l}31.66 \pm 6.33 € \\
\infty^{\wedge}\end{array}$ & 13.82 & $\begin{array}{l}0.001 \\
* *\end{array}$ \\
\hline GPX & $\begin{array}{l}28.78 \pm 2 . \\
42\end{array}$ & $\begin{array}{l}21.77 \pm 5.16 € \\
\infty^{\wedge}\end{array}$ & $\begin{array}{l}12.36 \pm 5.67 € \infty \\
\wedge \$\end{array}$ & $\begin{array}{l}24.16 \pm 6.56 \infty 0 \\
\$ \#\end{array}$ & 22.31 & $\begin{array}{l}0.001 \\
* *\end{array}$ \\
\hline SOD & $\begin{array}{l}56.63 \pm 5 . \\
43\end{array}$ & $\begin{array}{l}27.45 \pm 8.3 € \infty \\
\wedge\end{array}$ & $\begin{array}{l}15.29 \pm 7.39 € \infty \\
\wedge \$\end{array}$ & $\begin{array}{l}30.24 \pm 7.3 € \infty \\
\wedge \#\end{array}$ & 33.11 & $\begin{array}{l}0.001 \\
* *\end{array}$ \\
\hline
\end{tabular}

$€=$ Sig against group I $\infty=$ Sig against group II ${ }^{\wedge}=$ sig \&group III $\$=$ sig \& group IV \#=sig \& group $\mathrm{V}$

$*=$ Sig $\quad * *=$ highly significant 
Figure (1): A photomicrograph of a section in rat's liver prepared from control group showing normal hepatic plates radiating from a thin walled central vein (arrow1) separated by blood sinusoids (black arrows), polyhedral hepatocytes contained rounded vesicular nuclei (white arrows) (H\&E, $\mathbf{x} 40)$.

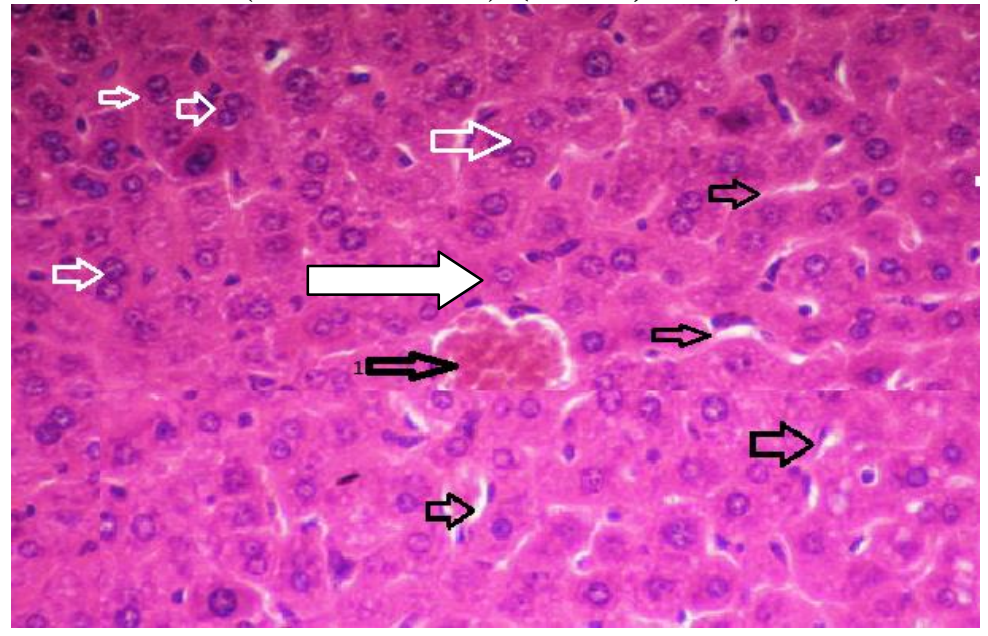

Figure (2): A photomicrograph of a section in rat's liver prepared from BPA treated group showing congested dilated central vein (star) and dilated blood sinusoids (arrow) (H\&E, x 20).

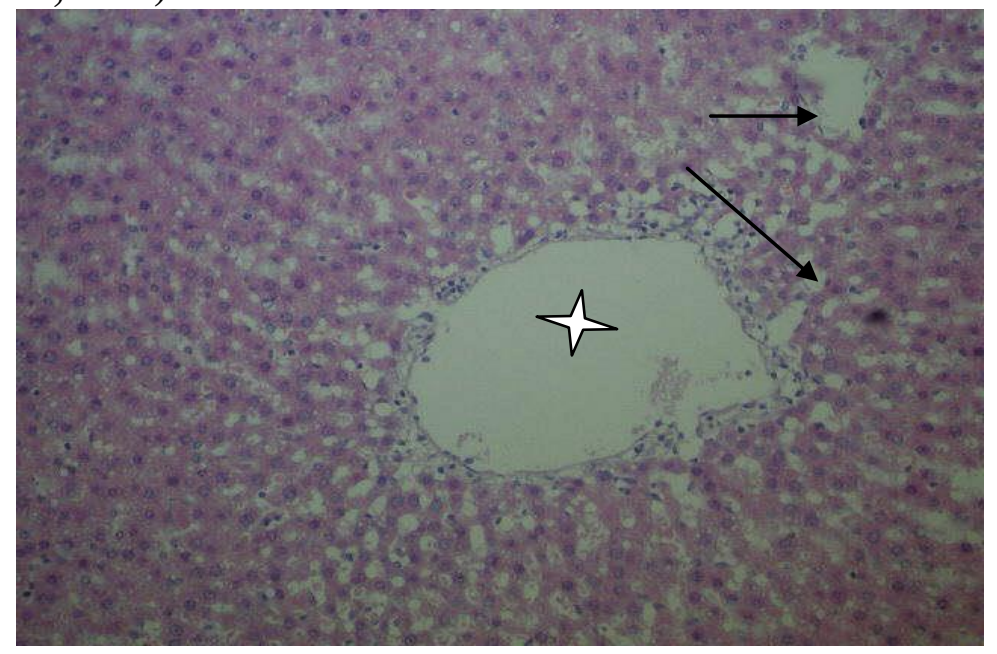

Figure (3): A photomicrograph of a section in rat's liver prepared from BPA treated group showing hydropic degeneration of hepatocytes(arrows)(H\&E, $x$ 40).

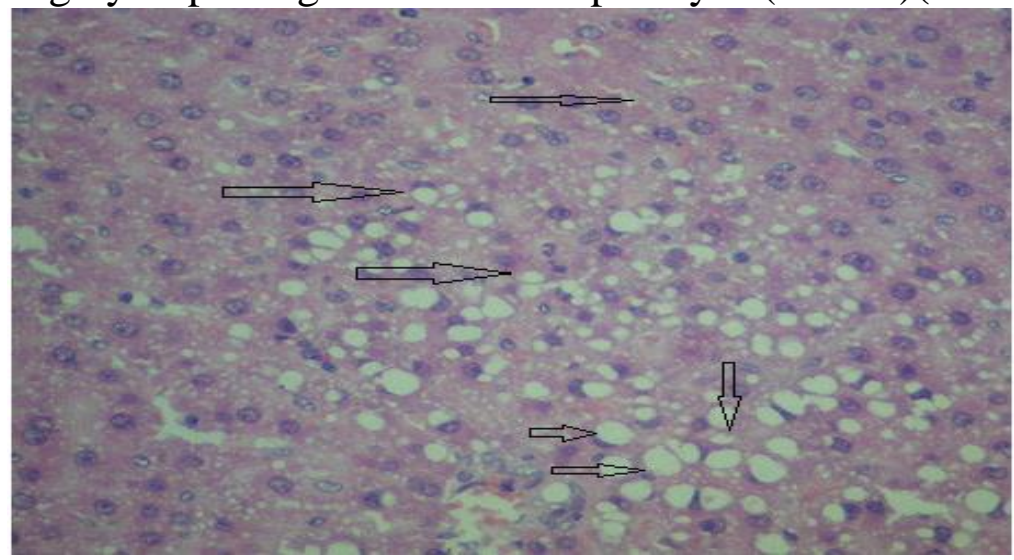


Figure (4): A photomicrograph of a section in rat's liver prepared from BPA treated group showing inflammatory cell infiltration of portal tract $(\mathbf{H \& E}, \mathbf{x} 40)$.

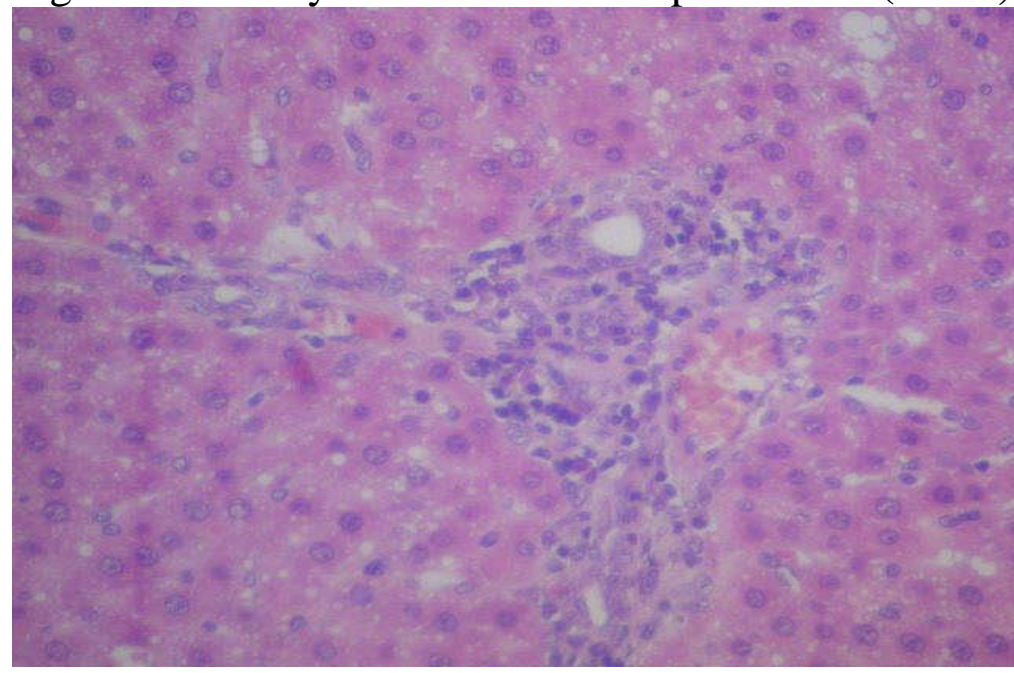

Figure (5): A photomicrograph of a section in rat's liver prepared from rat treated with BPA + vitamin C in high dose showing hydropic degeneration of hepatocytes (white arrows)\& dilated blood sinusoids (black arrows)(H\&E, x 40).

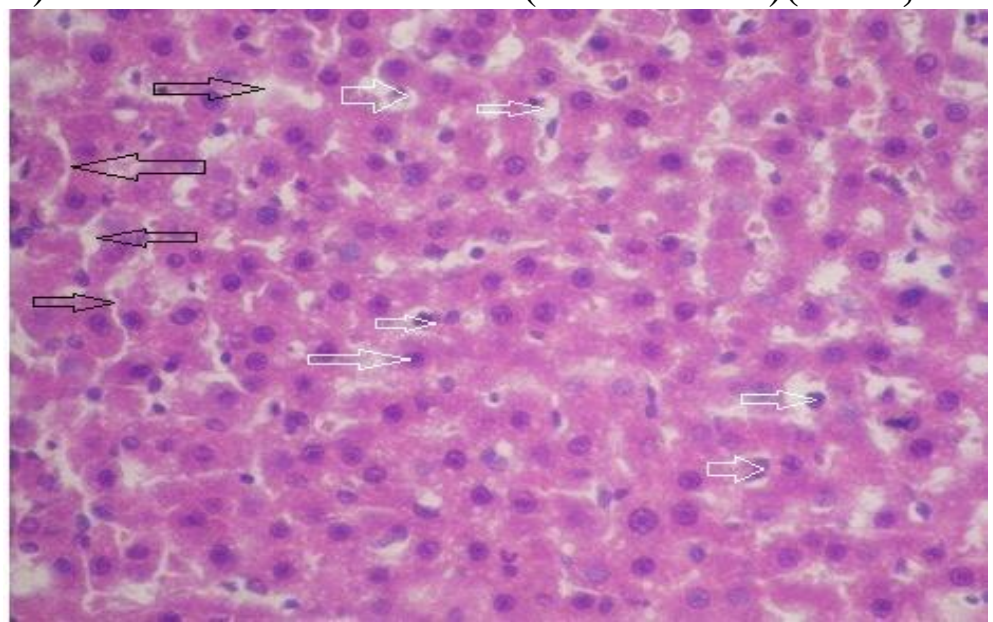

Figure (6): A photomicrograph of a section in rat's liver treated with BPA + high dose of vitamin $\mathbf{C}$ showing mononuclear cell infiltration of portal tract (black arrow)), dilated blood sinusoids(white arrows)(H\&E, $\mathbf{x} 40)$.

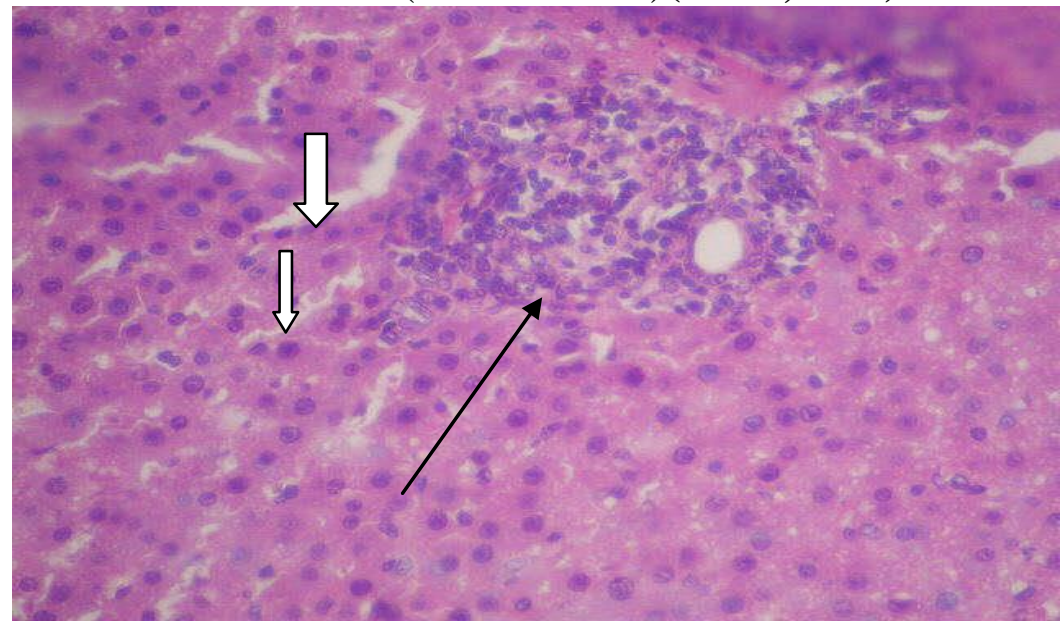


Figure (7): A photomicrograph of a section in rat's liver prepared from bisphenol A + low dose of vitamin $C$ treated group showing dilated central vein $(\mathrm{CV})$ and dilated blood sinusoids (arrows) (H\&E, x 400).

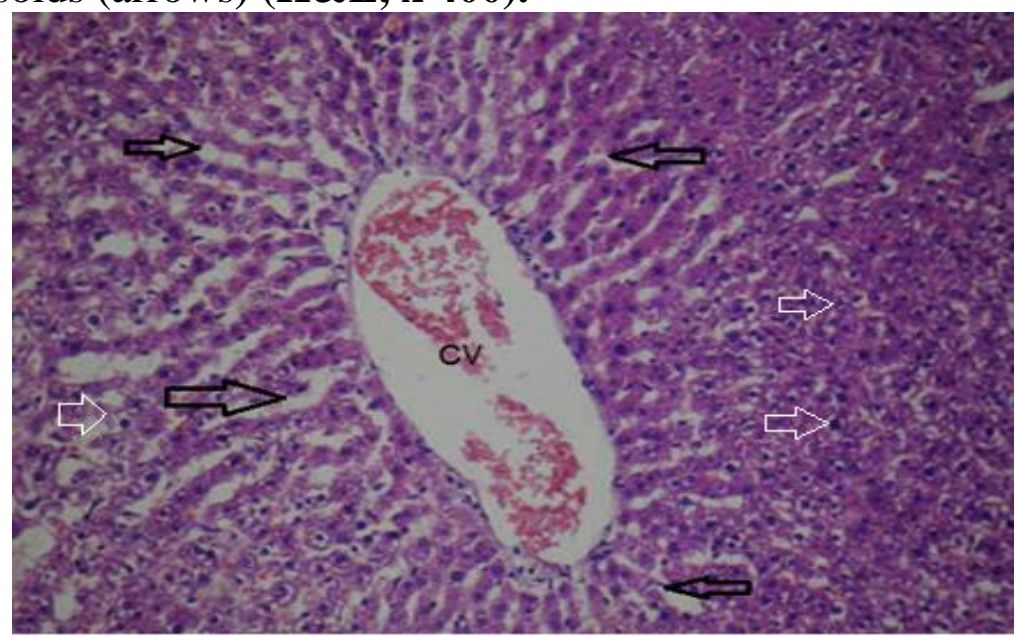

Figure (8): A photomicrograph of a section in rat's liver prepared from bisphenol A + low dose of vitamin $\mathrm{C}$ treated group showing mononuclear cell infiltration in portal tract (black arrow) and hydropic degeneration of hepatocytes (white arrows) (H\&E, $x$ 400).

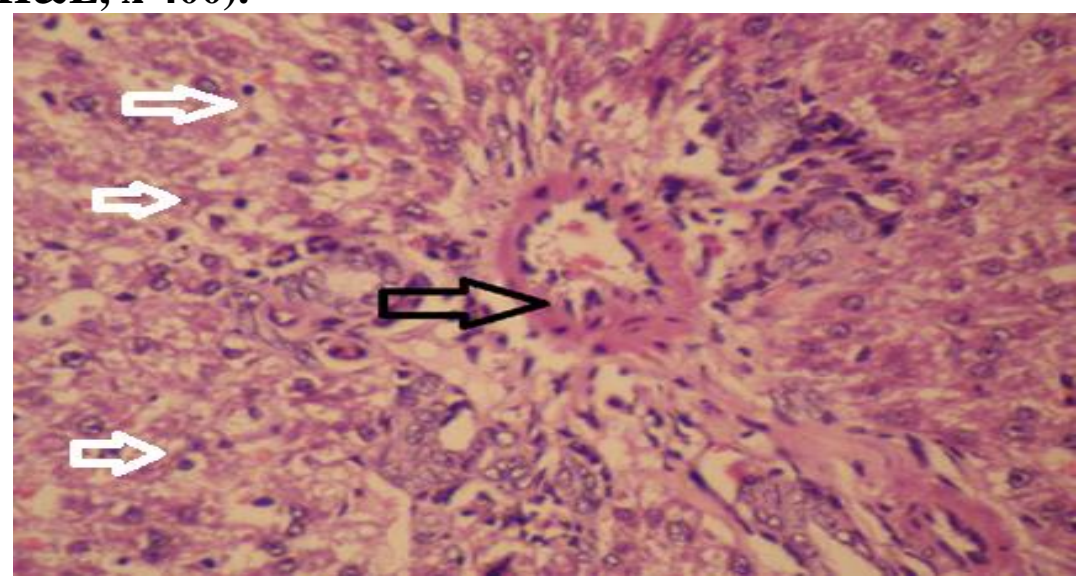

Figure (9): A photomicrograph of kidney section of rat from controlgroup showing normal histological structure: renal corpuscles contain normal glomerular tuft (GT) \& normal urinary space (U), proximal convoluted tubules (black arrows), and, distal convoluted tubules (white arrows)(H\&E, $\mathbf{x} 40)$.

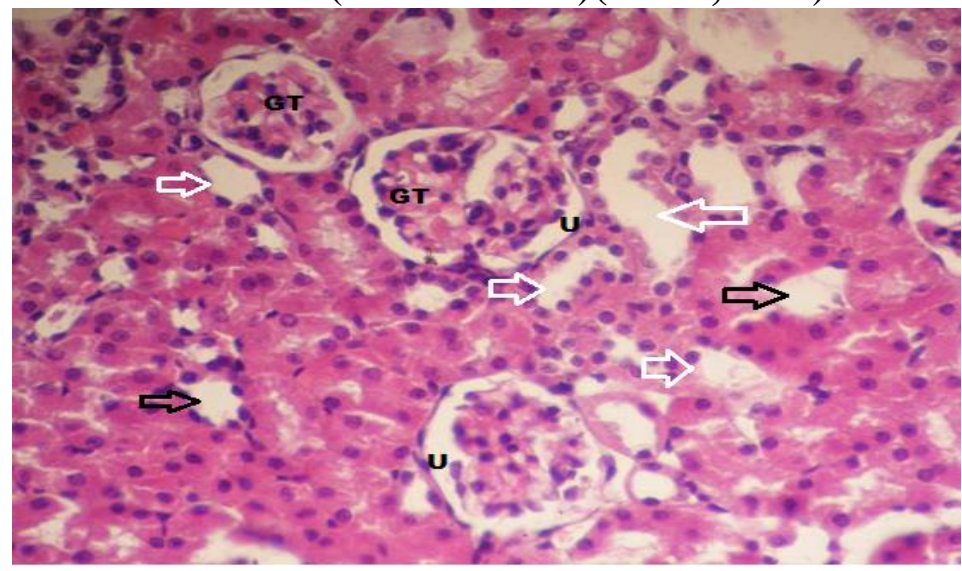


Figure (10): A photomicrograph of kidney section of treated rat with bisphenol A (group B) showing atrophied renal corpuscles (white arrow) with contracted glomerular tuft (GT) and wide urinary space (U), and atrophy of renal tubular epithelium with luminal dilatation (black arrows)(H\&E, x40).

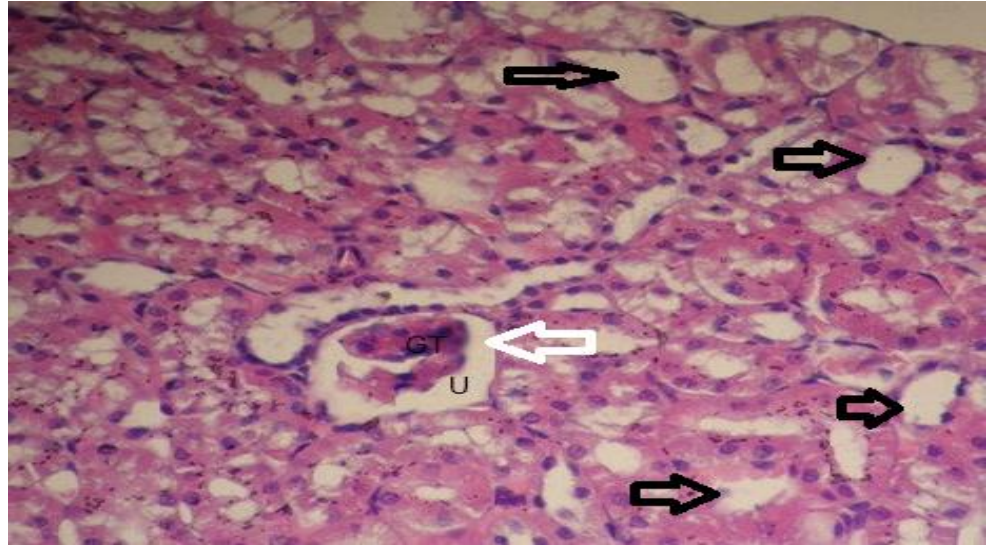

Figure (11): A photomicrograph of a kidney section of treated rat with $\mathrm{BPA}+$ high dose of vitamin $\mathrm{C}$ showing atrophied renal corpuscles with contracted glomerular tuft (GT) and wide urinary space (U), and degeneration of renal tubular epithelium with luminal dilatation (RT) (H\&E, x400).

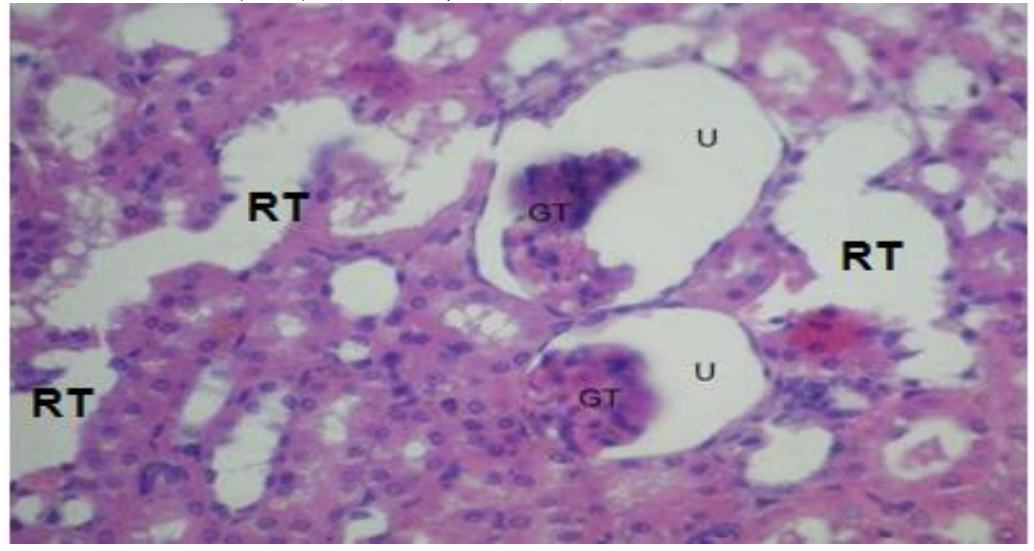

Figure (12): A photomicrograph of a kidney section of treated rat with BPA + low dose of vitamin $\mathrm{C}$ showing atrophied renal corpuscles with contracted glomerular tuft (GT) and wide urinary space (U), and degeneration of renal tubular epithelium with luminal dilatation (RT) (H\&E, x400).

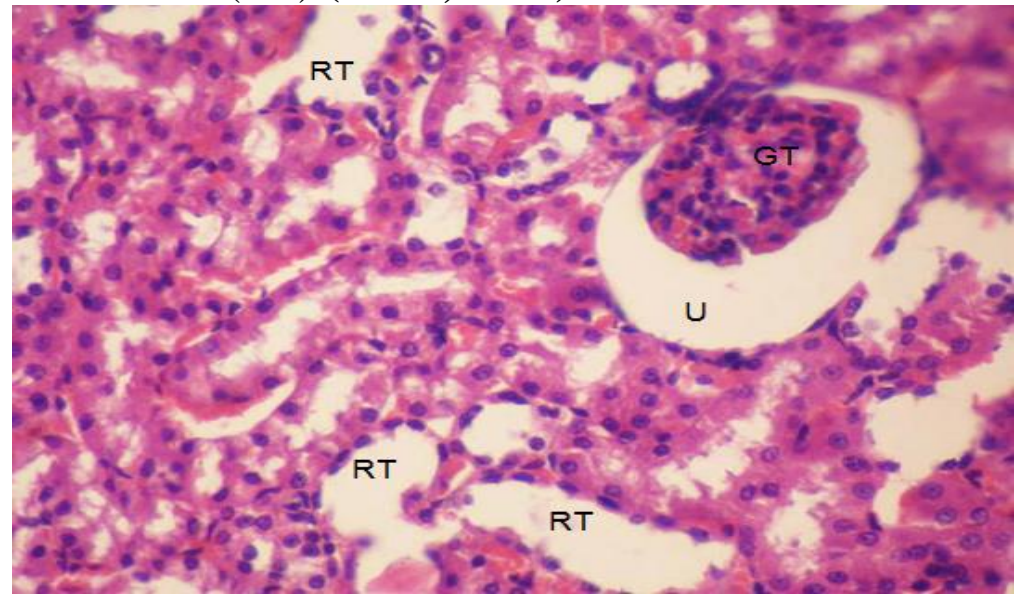


Figure (13): Electron micrograph of rat liver from control group showing normal nucleus. Normal mitochondria (black arrows),normal rough endoplasmic reticulum (arrow 1), and normal bile canaliculus (arrow 2) (TEM x3000).

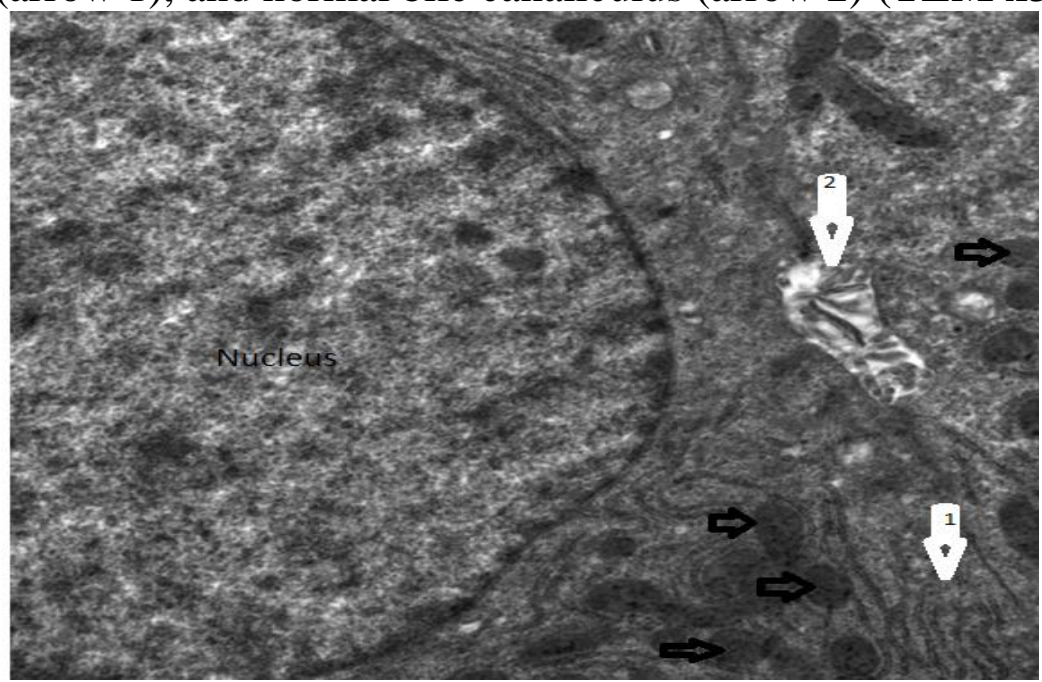

Figure (14): Electron micrograph of rat liver treated with bisphenol A showing mitochondrial swelling (arrows) (TEM x3000).

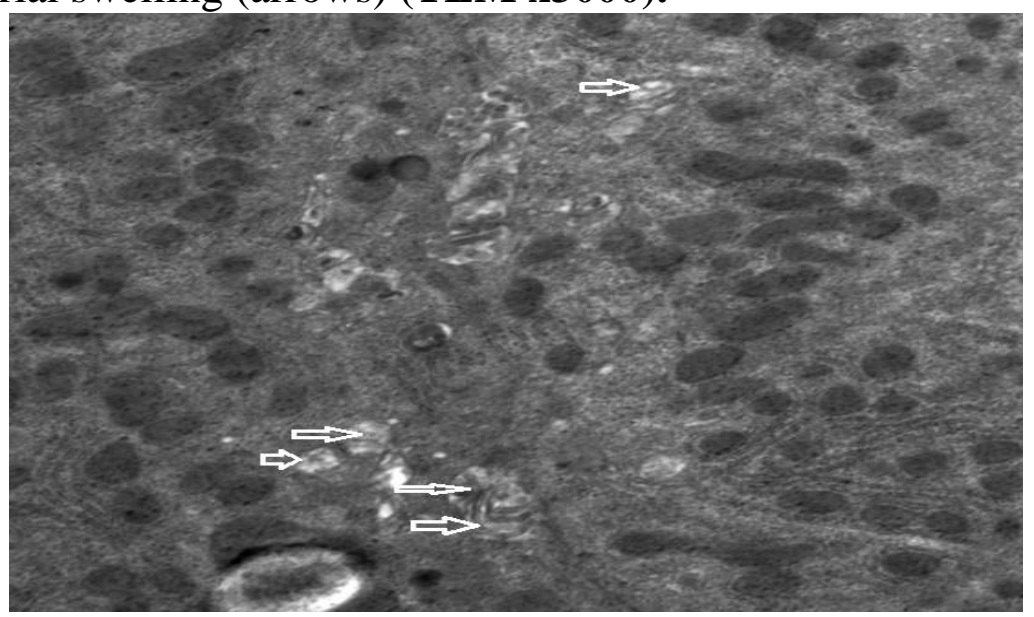

Figure (15): Electron micrograph of rat liver treated with bisphenol A showing accumulation of lipid droplets (arrows) \& swollen mitochondria (arrow 1) (TEM x3000),

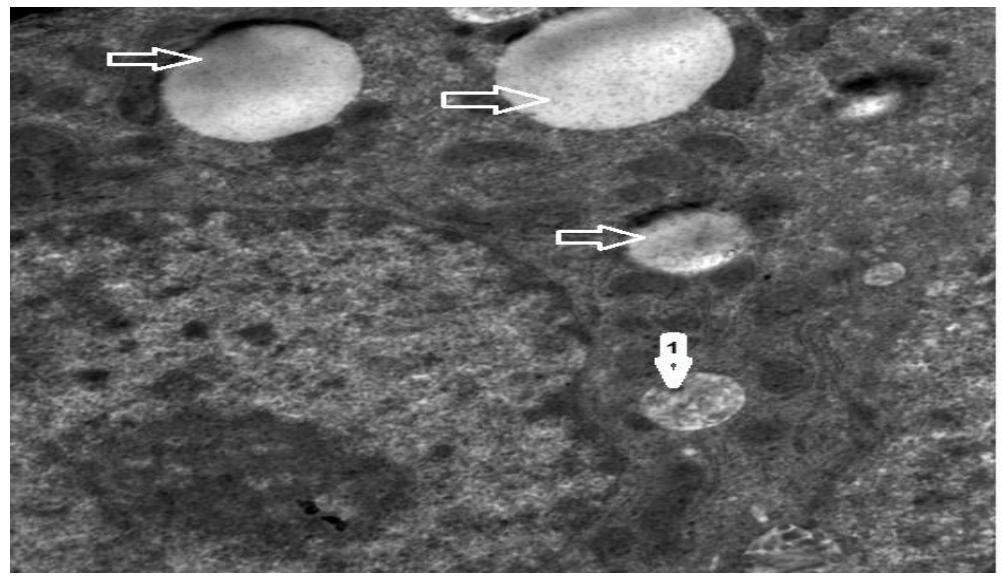


Figure (16): Electron micrograph of rat liver treated with $\mathrm{BPA}+$ vitamin $\mathrm{C}$ in high dose showing lipid droplet and mitochondrial swelling (arrows)(TEM x3000).

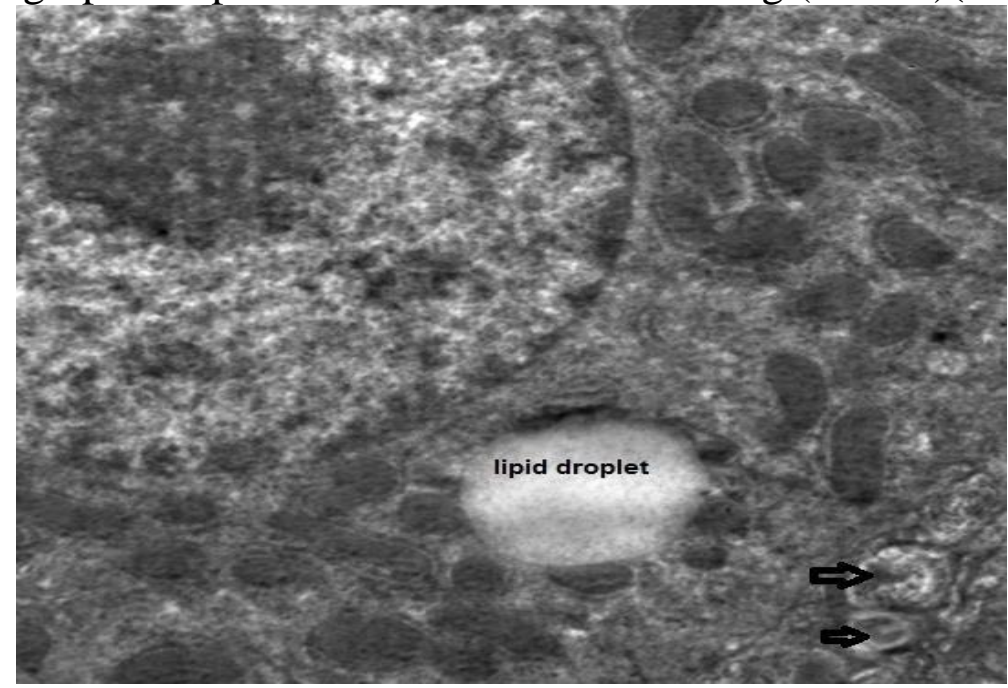

Figure (17): Electron micrograph of rat liver treated with bisphenol $\mathrm{A}+$ vitamin $\mathrm{C}$ in high dose showing accumulation of lipid droplets (arrows) (TEM x1500)

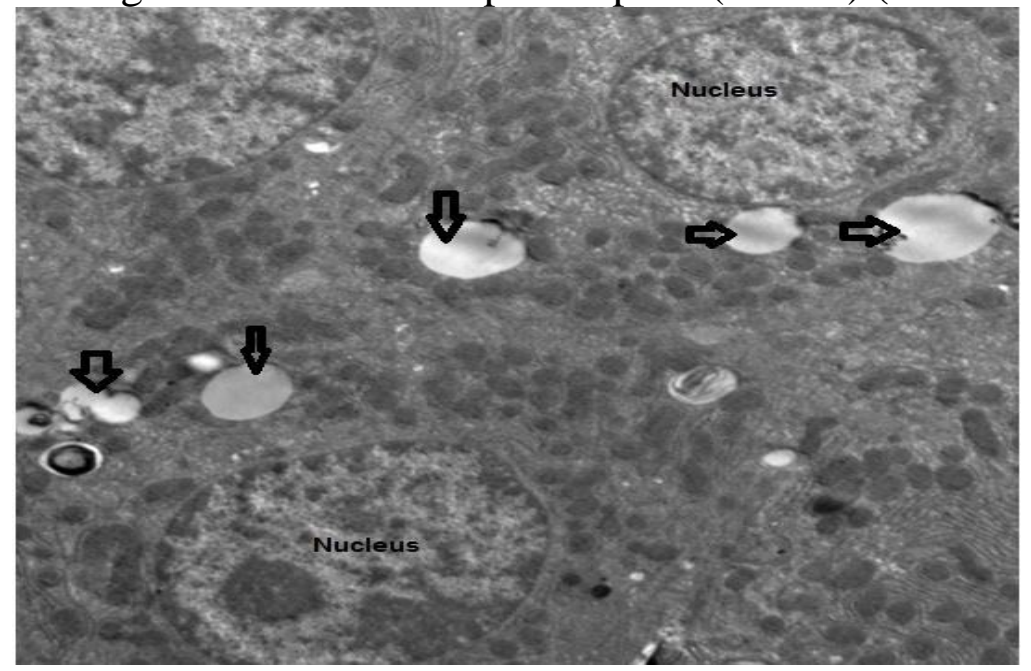

Figure (18): An electron photomicrograph of a section of rat liver treated with bisphenol $\mathrm{A}+$ low dose of vitamin $\mathrm{C}$ showing accumulation of lipid droplets (black arrow) \& mitochondrial swelling (white arrows) (TEM x3000)

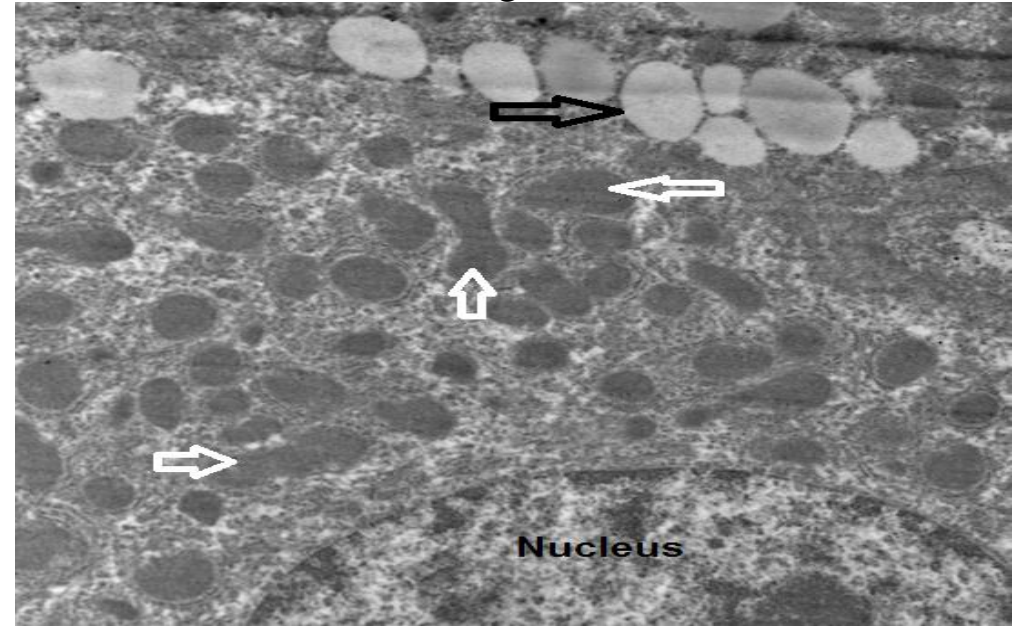


Figure (19): Electron micrograph of rat kidney from control group showing normal foot processes of podocytes (black arrows) \& normal thickness of basement membrane (white arrows) (TEM x5000)

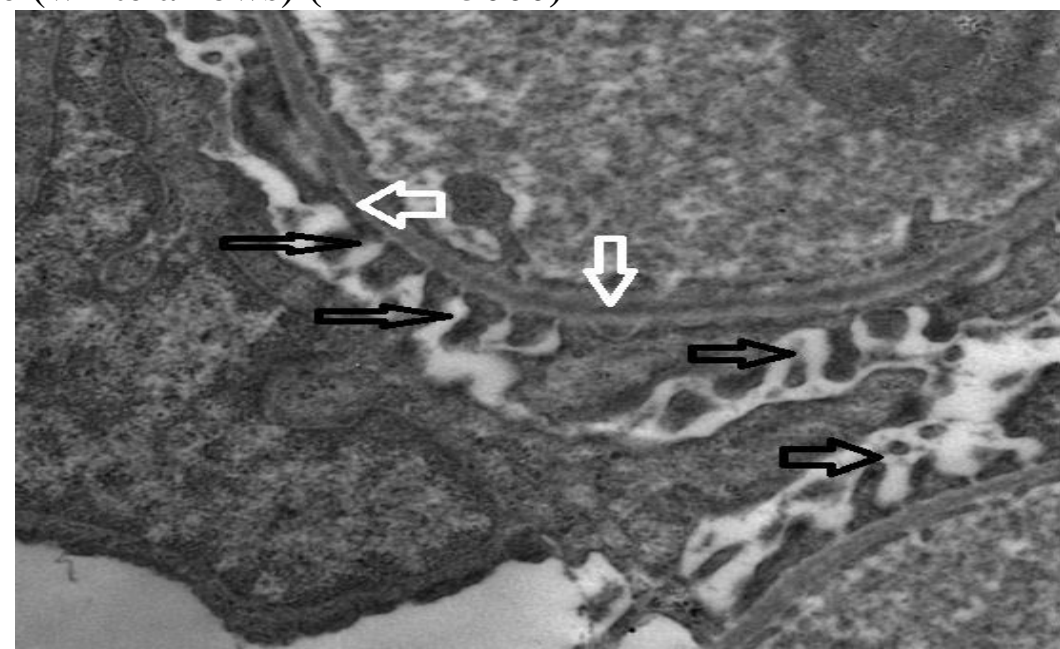

Figure (20): Electron micrograph taken from kidney of rat treated with bisphenol A showing enlarged foot processes of podocytes (black arrows) \& thickening of basement membrane (white arrows) (TEM x5000)

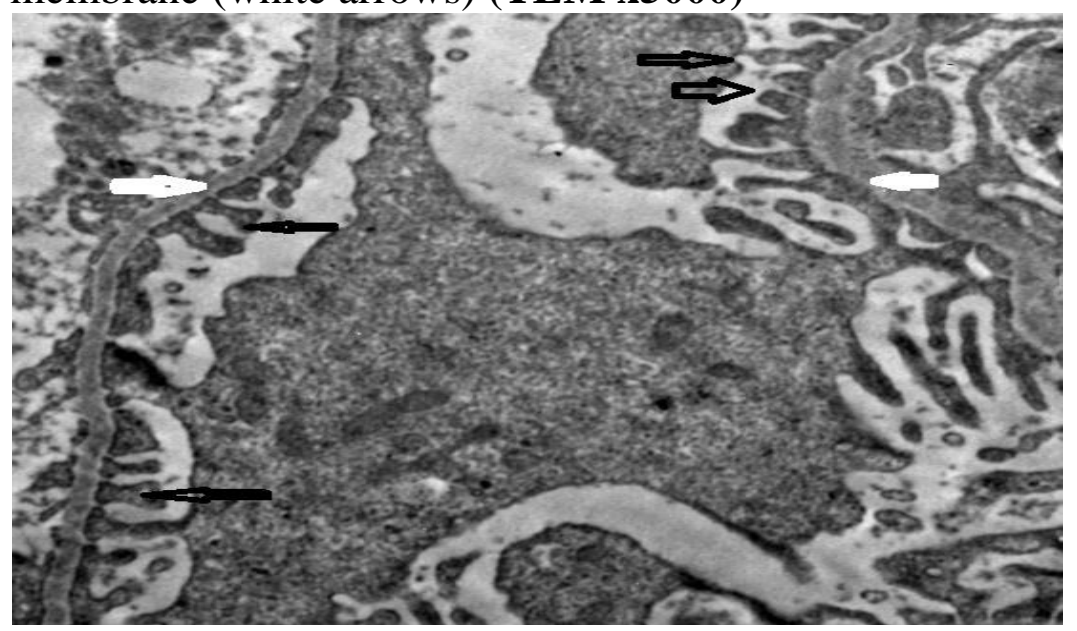

Figure (21): Electron micrograph taken from kidney of rat treated with bisphenol A and vitamin $C$ showing enlarged foot processes of podocytes (arrows)(TEM x2000).

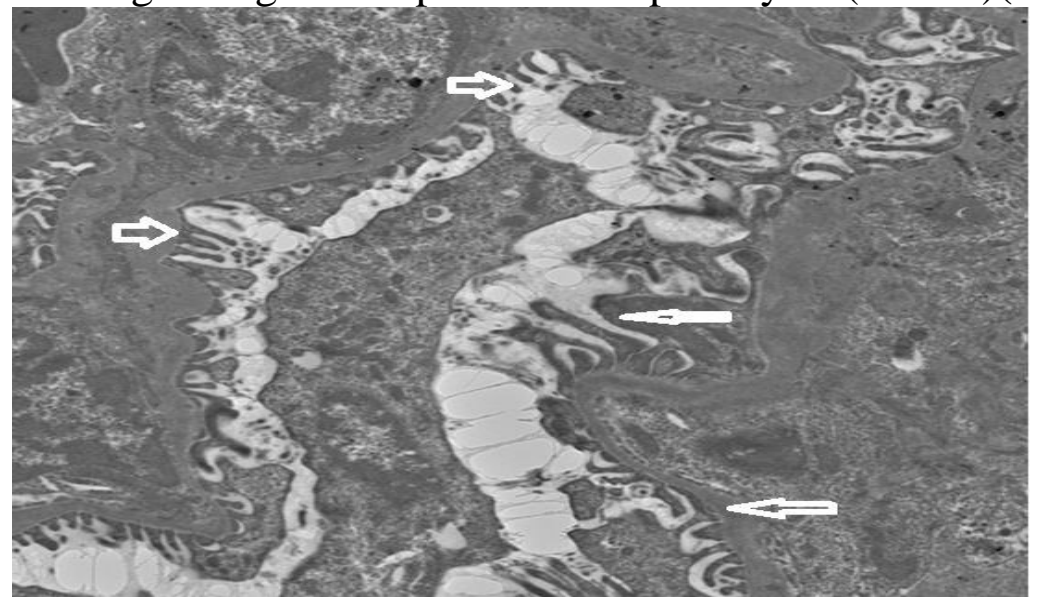


Figure (22): An electron photomicrograph taken from kidney of rat treated with bisphenol + low dose of vitamin $\mathrm{C}$ showing enlarged foot processes of podocytes (black arrows) \& thickening of basement membrane (white arrow) (TEM x5000).

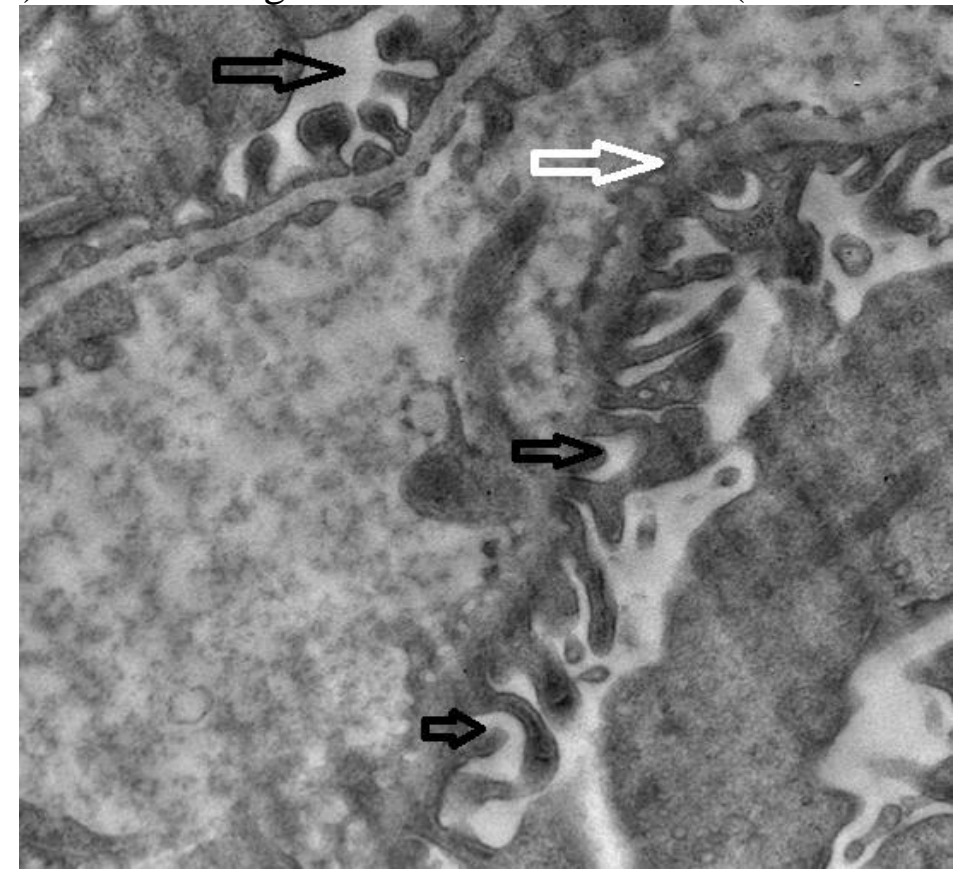

\section{DISCUSSION}

Bisphenol-A has been demonstrated in both in vivo and in vitro experiments to act as an endocrine disrupting chemical released into the environment (Richter et al., 2007). The majority of reported BPA toxicity studies in literature have focused on reproductive effects of these chemicals (Aydogan and Barlas, 2006). Besides its inherent effects on endocrine system, BPA is also known to inflict oxidative stress by affecting the redox status in the exposed organs (Hasselberg et al., 2004).

Vitamin $\mathrm{C}$ is a very powerful antioxidant agent. One major function of vitamin $\mathrm{C}$ is to protect tissues from harmful oxidation products (Korkmaz and Kolankaya, 2009). However, there are limited data concerning the effect of vitamin $\mathrm{C}$ on endocrine disrupting chemical (EDC) induced oxidative stress in tissues. Chitra et al. (2003) have suggested that co- administration of BPA and vitamin $\mathrm{C}$ had a protective effect on BPA-induced toxicity on the epididymis. At the beginning of the study, we hypothesized that vitamin $\mathrm{C}$ could act as an antioxidant against BPA induced oxidative damage in rats.

The present study revealed that BPA induced hepatotoxicity as there were significant increase in aspartate aminotransferase (AST), and alanine aminotransferase (ALT) over control values in BPA treated group, significant increase in MDA which is a marker of lipid peroxidation (one of the chief mechanisms of cell damage) in BPA treated group against control group, and the present study also revealed significant $(p<0.05)$ reduction in activities of enzymatic antioxidants such as superoxide dismutase (SOD), catalase (CAT), and glutathione peroxidase (GPX) in BPA treated group as compared to control. Data from the present study demonstrated that bisphenol-A induced oxidative 
stress by reducing antioxidative capacity of the liver.

The present results are in agreement with those of Korkmaz et al. (2010) who reported a significant increase in ALT and AST levels in rats treated with $25 \mathrm{mg} / \mathrm{kg}$ BPA for 50 days. These results are also in accordance with the study of Neha et al., (2012) who found a significant increase in AST and ALT levels in mice treated with BPA $(50 \mathrm{mg} / \mathrm{kg})$ for 30 days. The study of Walaa et al., (2015), revealed that the activities of serum ALT and AST exhibited a significant increase in BPA treated group compared to control group.

The results of the current study are in accordance with the findings of previous study which had demonstrated the involvement of oxidative stress and lipid peroxidation in BPA exposure had induced liver toxicity (Lam et al., 2011).In line with this, another study reported that BPA induced damage was associated with oxidative stress (Hassan et al., 2012). The study done by Korkmaz et al. (2010), showed significant increase in MDA level in the liver tissues of rats of BPA treated group as compared to control group.

The results of the current study are also in agreement with Asahi et al., (2010) who revealed that BPA increased the generation of reactive oxygen species (ROS) and induced cellular apoptosis in hepatocytes. Moon et al., (2012) indicated that BPA can induce hepatic damage and mitochondrial dysfunction by increasing oxidative stress in the liver.

The results of the present study are in agreement with the study of Bindhumol et al. (2003)who found that bisphenol A generated ROS by decreasing the activities of antioxidant enzymes, (superoxide dismutase, catalase, glutathione reductase and glutathione peroxidase) in mitochondrial and microsome-rich fractions of liver.

The results of the present study are also in agreement with the study of Hassan et al.,(2012) who found reduction in both hepatic reduced glutathione (GSH) and glutathione peroxidase (GSHPX) levels in rats treated with BPA $(25 \mathrm{mg} / \mathrm{kg} /$ day $)$ for 30 days. As the increase in GSH level is important for GSHPX, which requires GSH as a cofactor, and the elevation in GSH level increases activity of GSHPX.

The results of the present study contradicted with Bindhumol et al., (2003), who found that the activity of alanine transaminase (ALT) remained unchanged in BPA treated rats as compared with the corresponding control rats.AST and ALT enzymes are the most reliable markers of hepatocellular injury or necrosis. Their levels are elevated in a variety of hepatic disorders. Of the two, ALT is thought to be more specific for hepatic injury because it is present mainly in liver cystosol and in low concentration elsewhere (Giboney, 2005). When the liver hepatocytes are damaged, these enzymes are released into the blood where the significant increase in AST and ALT levels indicates the damage to the cystosol and also to mitochondria (Mathuria and Verma, 2008).

Regarding the histopathology of the liver in BPA treated group, the present study revealed changes in hepatic architecture in the form of vacuolation and hydropic degeneration of hepatocytes. Similar observations were recorded by previous studies of Hassan et al., (2012), Hussein and 
Eid, (2013), and Roy et al., (2011). In addition, dilated congested central vein, dilated blood sinusoids, and, mononuclear cell infiltration in portal tract and in interstitial tissue were detected. These findings agreed with the results recorded by Daniela-Saveta et al., (2014).

The histopathological changes in the liver may be explained the ability of BPA to induce apoptosis and cell damage by the induction of adenylate kinase activation, TNF-alpha gene expression, dysregulation of $\mathrm{Ca}^{+2}$ homeostasis, and production of ROS (Reactive Oxygen Species) (Lee et al., 2008 and Kovacic, 2010).

Regarding electron microscopic study of the liver in BPA treated group, the current study revealed mitochondrial swelling, and lipid accumulation in the liver cells.

The results of the present study are in accordance with the study of Wei et al., (2014) who found that BPA induced mitochondrial swelling during in vitro study when mitochondria isolated from neonatal rat liver were treated with $\mathrm{BPA}$ at $30^{\circ} \mathrm{C}$ for 55 minutes,

BPA acts directly on mitochondria, altering mitochondrial ultrastructure, inducing permeability transition (PT) and releasing proteins that lead to activation of apoptosis. In addition, the release of apoptogenic proteins from the mitochondria induced by BPA was further demonstrated to cause condensed chromatin in isolated liver nuclei (Snyder et al., 2000).

As regard lipid accumulation in the liver cells, this result agreed with Huc et al., (2012)who made invitro study and reported that BPA-induced lipid accumulation in HepG2 cells by disturbing mitochondrial function which has been implicated in the pathogenesis of hepatic steatosis.

The present study revealed that BPA induced nephrotoxicity by significant increase in malondialdehyde(MDA) which is a marker of lipid peroxidation (one of the chief mechanisms of cell damage) in BPA treated group against control group, significant $(p<0.05)$ reduction in activities of enzymatic antioxidants such as superoxide dismutase (SOD), catalase (CAT), and glutathione peroxidase (GPX) in bisphenol A treated group as compared to control, also there were significant increase in uric acid \&creatinine levels in BPA treated group as compared to control group.

The results of the present study are in agreement with the study of Korkmaz et al., (2009), that revealed significant increase in MDA levels in renal tissue of rats treated with BPA $(50 \mathrm{mg} / \mathrm{kg})$ for 50 days as compared to control group. Similarly, some previous works have been demonstrated that BPA generates ROS that caused oxidative damage in the brain, reproductive tract and kidney of rats (Aydogan et al., 2008 and Aydogan et al., 2009).

The results of the present study are also in agreement with the study of Korkmaz et al., (2009), that revealed significant reduction in GSH- based antioxidant enzymes system including glutathione peroxidase (GPX), and glutathione reductase (GR) in renal tissues in BPA treated group as compared to control group.

There are similarities between the renal function alteration detected in the present study and those described by previous authors who found increase in creatinine and Blood Urea Nitrogen 
(BUN) levels due to BPA exposure(Yildiz\&Barlas, 2013 and Daniela-Saveta et al., 2014).

In agreement with the results of the current study, Murmu and Shrivastava, (2014), showed that BPA insignificantly increased the creatinine level after 15, 30 and 60 days administration in fresh water fish (Cirrhinusmrigala) as compared to control.

Bisphenol A has a nephrotoxic effect due to accumulation of BPA toxic metabolites and inability of the kidney to eliminate those (Sangai et al., 2012). Several toxic substances that induced nephrotoxicity may result in alteration of glomerular basement membrane and affecting glomerular filtration rate (Manikkam et al., 2013).

The results of the present study are also in agreement with the study of Mourad and Khadrawy, (2012) who found a significant increase in uric acid concentration occurred after 6 weeks of the daily oral administration of BPA at both the high $(25 \mathrm{mg} / \mathrm{kg})$ and low $(10$ $\mathrm{mg} / \mathrm{kg}$ ) dose levels.

It has been demonstrated that serum uric acid levels are significantly elevated in non-alcoholic fatty liver patients (Li et al., 2009). Marmugi et al. (2011) suggested that low doses of BPA may influence de novo fatty acid synthesis thereby contributing to hepatic steatosis. Furthermore, uric acid increase may be due to the effect of BPA on the heart as several studies showed an association between elevated uric acid levels andcardiovascular diseases (Fang and Alderman, 2000).

On contrast to the results of the present study, non-significant changes in lipid peroxidation and reduced glutathione (GSH) levels and in the activity of catalase enzyme had been detected in rat renal tissue after the daily oral administration of BPA at the two dose levels $(5,10 \mathrm{mg} / \mathrm{kg})$. The only significant changeobtained was an increase in Glutathione-S-Transferase (GST) activity after 6 weeks of oral administration of $25 \mathrm{mg} / \mathrm{kg}$ of BPA (Mourad, \& Khadrawy, 2012).

Regarding the histopathology of the kidney in rats treated with BPA, the present study revealed atrophy of renal corpuscles with retraction of glomerular tuft, widening of urinary space, with degenerative changes of renal tubules, and mononuclear cell infiltration. These results are in agreement with the study of Walaa et al., (2015) and Korkmaz et al., (2009).

This may be explained by the ability of BPA to produce reactive oxygen species causing oxidative damage and may lead to mitochondrial injury consequently playing an important role in apoptotic mechanisms (Al-shobaili et al., 2013).

Regarding electron microscopic study of the kidney in BPA treated group, the present study revealed enlargement of foot processes of podocytes, and thickening of basement membrane of Bowman's capsule.

The results of the present study are in accordance with the study of OleaHerreroet al., (2014) who found that intraperitoneal injection of bisphenolA in mice at dose of $50 \mathrm{mg} / \mathrm{Kg}$ for 5 weeks induced an enlargement of both cytoplasm and foot processes of podocytes as well as the presence of condensed chromatin, suggesting apoptosis. This is in line with the study of Walaa et al., (2015) which revealed that BPA induced thickening of the basement membrane of Bowman's 
capsule which confirmed by strong Periodic acid Schiff (PAS) stainability. Several toxic substances induced nephrotoxicity may result in alteration of the glomerular basement membrane and affecting the glomerular filtration (Manikkam et al., 2013).

BPA was able to induce podocyte hypertrophy by its effect on the podocyte expression of the cyclinedependent kinase inhibitor p27Kip1, which is known to play a key role in the mechanism of renal cell hypertrophy beside its effect on Transforming Growth Factor- $\beta 1$ (TGF$\beta 1$ ) system (Ziyadeh \& Wolf, 2008 and Romero et al., 2010).

The findings of the present study clearly indicated the involvement of oxidative stress caused by generation of reactive oxygen species in bisphenol-A induced hepatotoxicity and nephrotoxicity. Bisphenol A is lipophilic in nature, so it can easily penetrate and interact with the lipid content of cell membrane. Oral administration of bisphenol A for 6 weeks has resulted in significant elevation in MDA levels which could be due to overproduction of reactive oxygen species and suppression of antioxidant enzymes levels resulting in the altered redox potential of cell causing lipid peroxidation and cell damage. Several studies reported the occurrence of oxidative toxicity after bisphenol-A exposure in rats and mice (Doerge \& Fisher, 2010 and Gong and Han, 2006).

Enzymatic antioxidants include superoxide dismutase (SOD), catalase, glutathione peroxidase (GPX), and glutathione-s-transferase (GST), which constitutes the first line defense against reactive oxygen species (ROS) induced damage (Droge, 2002). Catalase and glutathione peroxidase (GSHPX) catalyze dismutation of the superoxide anion $\left(\mathrm{O}^{-2}\right)$ into hydrogen peroxide $\left(\mathrm{H}_{2} \mathrm{O}_{2}\right)$ which then convert hydrogen peroxide to water, providing protection against reactive oxygen species (Sayed-Ahmed et al., 2010).Therefore, the damage at the cellular level by oxidants is attenuated by antioxidant enzymes such as SOD, GSHPX, and CAT (Koc et al., 2005).

The significantly reduced activities of antioxidant enzymes might be due to BPA induced protein oxidation. The interaction of lipid peroxidation (LPO) products with enzyme molecules leads to the exclusive modification of histidine residue and generation of protein-protein cross linked derivatives causing reduction in enzyme activity (Kwon et al., 2000).

The results of the present study revealed reduction in AST, ALT, and non significant improvement in MDA in rats treated with bisphenol $\mathrm{A}$ and vitamin $\mathrm{C}$ in low dose as compared to BPA treated group and -ve control group. There was also non significant improvement in antioxidant enzymes (CAT, SOD, and GPX) in the liver in the same group as compared to bisphenol A treated group and -ve control group. Also, there were reduction in AST, ALT, and significant reduction in MDA in rats treated with bisphenol $\mathrm{A}$ and vitamin $\mathrm{C}$ in high dose as compared to BPA treated group and -ve control group. There was significant reduction in antioxidant enzymes (CAT, SOD, and GPX) in the liver in the same group as compared to bisphenol-A treated group and -ve control group.

The results of the present study are in accordance with the study of Korkmaz et al., (2010)s who found 
that serum ALT and AST levels were significantly higher $(\mathrm{P}<0.05)$ in $\mathrm{BPA}$ and $\mathrm{BPA}+$ vitamin $\mathrm{C}$, treated groups when compared to control group of rats. In addition, serum ALT levels in the BPA + vitamin C treated group were significantly higher compared to BPA treated group $(\mathrm{P}<0.05)$. Also they found that malondialdehyde (MDA) levels were significantly higher in BPA + vitamin C treated group when compared to BPA treated group and control group $(\mathrm{P}<0.05)$. On the other hand, there was significant reduction in the liver catalase (CAT), superoxide dismutase (SOD), and glutathione peroxidase $(\mathrm{GPX})$ in $\mathrm{BPA}+$ vitamin $\mathrm{C}$ treated group as compared to BPA treated group and control group.

The results of the present study contradicts with the study of Bindhumol et al., (2003) who found that co-administration of vitamin $\mathrm{C}$ reversed the effect of BPA induced oxidative stress in the liver of rats.

Regarding the histopathology of the liver in rats treated with BPA + vitamin $\mathrm{C}$ in high \& low doses, there were more hydropic degeneration of hepatocytes, dilated blood sinusoids and, marked inflammatory cell infiltration in interstitial tissue and in portal tracts.

These results are in accordance with the study of Korkmaz et al., (2010) who revealed that vitamin $\mathrm{C}$ coadministration with BPA resulted in more severe hepatic congestion, more necrotic areas, and mononuclear cell infiltration when compared to BPA treated group,

Regarding electron microscopic study of the liver in rats treated with $\mathrm{BPA}+$ vitamin $\mathrm{C}$, in high \& low doses the current study revealed mitochondrial swelling, and lipid accumulation in the liver cells.

In the kidney, the results of the present study revealed a significant increase in MDA level in renal tissues in $\mathrm{BPA}+$ high dose of vitamin $\mathrm{C}$ treated group as compared to BPA treated group and control group. On the other hand, there was a non significant increase in MDA production in kidney in group VI (BPA + low dose of vitamin $\mathrm{C}$ treated group) as compared to group I (-ve control group) \& a non significant reduction in its concentration in this group as compared to group IV (BPA treated group). Regarding renal antioxidants, the results of the present study revealed a significant reduction in renal CAT, GPX, and SOD concentrations in group $\mathrm{V}$ treated with (BPA + high dose of vitamin $\mathrm{C}$ ) as compared to group I (-ve control group) \& There was a significant reduction in GPX \& SOD and a non significant increase in CAT concentrations in this group as compared to group IV (BPA treated group). While in group VI (BPA + low dose of vitamin $\mathrm{C}$ treated group), there was a significant reduction in renal CAT, GPX, and SOD concentrations as compared to group I (-ve control group), also there was a non-significant increase in CAT, SOD, and GPX concentrations in this group as compared to group IV (BPA treated group).

These results are in accordance with the study of Korkmaz et al., (2009) who found that malondialdehyde (MDA) levels in the renal tissue were found to be higher in the BPA and BPA+ vitamin $\mathrm{C}$ treated groups compared with controls $(\mathrm{P}<0.05)$. Furthermore, higher MDA levels were detected in the BPA+ 
vitamin $\mathrm{C}$ treated group compared to the BPA treated group.

The results of the present study didn't agree with the study of Korkmaz et al., (2009), who found that serum creatinine level in the BPA + vitamin C treated group were significantly lower compared with BPA treated group, and that vitamin $\mathrm{C}$ co-administration with BPA did not produce significant increase in Blood Urea Nitrogen (BUN) \& uric acid concentration as compared to BPA treated group.

Regarding the histopathology of the kidney in rats treated with BPA + vitamin $\mathrm{C}$ in high \& low doses, the same histopathological changes of the kidney in rats treated with BPA were detected, including degenerated renal tubules and atrophied renal corpuscles.

These results are in accordance with the study of Korkmaz et al., (2009) who revealed that necrotic lesions, congestion areas, and mononuclear cell infiltration in the rat kidneys of $\mathrm{BPA}+$ vitamin $\mathrm{C}$ treated group were similar to those observed in BPA treated group.

Regarding electron microscopic study of the kidney in in rats treated with $\mathrm{BPA}+$ vitamin $\mathrm{C}$ in high \& low doses, the present study revealed enlargement of foot processes of podocytes similar to that of rats treated with BPA.

The unpredicted damaging effect of vitamin $C$ in this study may be explained by prooxidant effect, usually by interaction with transition metal ions. When $\mathrm{Fe}^{+3}$ is present, vitamin $\mathrm{C}$ can convert $\mathrm{Fe}^{+3}$ into $\mathrm{Fe}^{+2}$ which reacts with oxygen or hydrogen peroxide resulting in formation of hydroxyl radicals and superoxide anions (Rietjens et al., 2002).

\section{CONCLUSION}

- Oral administration of bisphenol-A in a dose of $25 \mathrm{mg} / \mathrm{kg}$ produced hepatotoxicity and nephrotoxicity by affecting oxidant/antioxidant balance in rat liver and kidney that proved by biochemical $\&$ histopathological changes.

- Co-administration of vitamin C in low dose $(5.5 \mathrm{mg} / \mathrm{kg})$ didn't prevent this oxidative damage. While coadministration of vitamin $\mathrm{C}$ in high dose $(60 \mathrm{mg} / \mathrm{kg})$ augmented this oxidative damage.

\section{RECOMMENDATION}

- Establishing a national policy that restrict bisphenol-A use and promote alternative approaches respecting health and environment.

- Widespread public education regarding the health hazards of BPA with a special concern about its systemic toxic effects, and encouraging the use of alternative methods for hardness of polycarbonate plastics and epoxy resins.

- Use glass, or polypropylene bottles instead of polycarbonate ones (hard, shiny,clear or tinted plastic, usually with a number 7 or "PC" on the bottom).

- To clean polycarbonate bottles, do not use harsh detergents or put bottlesin the dishwasher. Instead, clean them with warm soapy water and a sponge. Scouring brushes can scratch the surface of the bottles and increase leaching rates.

- Avoid heating foods in polycarbonate containers, as bisphenol A tends to leach faster with higher temperatures. Use glass or ceramic containers instead. 
- Avoid use of infant formula brands incans that use BPA as an epoxy liner.

- Cut back on consumption of canned foodsand beverages to reduce exposure to bisphenolA contamination from the interiorcoating of the container. Also, avoid cannedfoods with higher fat content, which mayhave higher levels of bisphenol A.

- Avoid use of high dose of vitamin $\mathrm{C}$ as antioxidant with exposure to BPA.

- Other studies are required to evaluate the toxic effects of BPA and the results of co-administration of vitamin $\mathrm{C}$.

- More studies are needed on vitamin $\mathrm{C}$ antioxidant and pro-oxidant properties.

\section{ACKNOWLEDGMENT}

Our deep gratitude and thanks to all staff members in Electron Microscopic Unit, Faculty of Medicine, Tanta University, for their great help and cooperation. Our great thanks to all of the staff members in Pathology Department, Faculty of Medicine, Benha University for their great help to finish this work. Lastly we would like to extend our thanks to all of the staff members in Forensic Medicine \& Clinical Toxicology Department, Faculty of Medicine, Benha University, for their help \& cooperation. www.fmed.bu.edu.eg

\section{REFERENCES}

\section{Al-Shobaili,H., Al-Robaee,A.,} Alzolibani, and Rasheed, $\mathbf{Z}$. (2013): Immunological studies of reactive oxygen species damaged catalase in patients with systemic lupus erythmatosis correlation with disease activity index.
Immunological Investigation, 42, 191-203.

Aydogan, M. and Barlas, N. (2006): Effects of maternal 4-tertoctylphenol exposure on the reproductive tract of male rats at adulthood. Reprod. Toxicol. 22, 455-460.

Aydogan, M., Korkmaz, A. , Barlas, N. and Kolankaya, D. (2008): The effect of vitamin $\mathrm{C}$ on bisphenol $\mathrm{A}$, nonylphenol and octylphenol induced brain damages of male rats. Toxicology, 249: 35-39.

Aydogan, M., Korkmaz, A., Barlas, N. and Kolankaya, D. (2009): Pro oxidant effect of vitamin $\mathrm{C}$ coadministration with bisphenol A, nonylphenol, and octylphenol on the reproductive tract of male rats. Drug Chem. Toxicol..

Bindhumol, V., Chitra, K.C. and Mathur,. PP. (2003): Bisphenol A induces reactive oxygen species generation in the liver of male rats.Toxicology 188:117-124.

Carr, A. and Frei, B. (1999:Does Vitamin $\mathrm{C}$ act as a pro-oxidant under physiological conditions? FASEB J;13:1007-24.

Chattopadhyay, A., Biswas, S., Bandyopadhyay, D., Sarkar, C. and Datta, A.G. (2003): Effect of isoproterenol on lipid peroxidation and antioxidant enzymes of myocardial tissue of mice and protection by quinidine. Molecular and Cellular Biochemistry 245, 4349.

Chitra, K.C., Rao, K.R. and Mathur, P.P. (2003): Effect of bisphenol A and coadministration of bisphenol $\mathrm{A}$ and vitamin $\mathrm{C}$ on epididymis of adult rats: a histopathological and biochemical study. Asian J. Androl. 5, 203-208. 
Daniela-Saveta, P., Bolfa, P., Bela, K ., Vlase, L., Paltinean, R., Anca, P., Catoi, C., Cran, G. and Loghin, F. (2014): Influence of GenistaTinctoria L or Methylparaben on Subchronic Toxicity of Bisphenol A in Rats. Biomedical and Environmental Sciences, 27: 85-96.

Doerge, D.R. and Fisher, J.W. (2010): Background paper on metabolism and toxicokinetics of bisphenol A. In FOOD, WHO/HSE/FOS/11.1. Expert meeting on bisphenol A (BPA) Ottawa, Canada, 2-5 November, pp. 1-20.

Droge, W. (2002): Free radicals in the physiological control of cell function. Physiol Rev., 82(1): 47 95.

European Chemicals Bureau (ECB) (2008): European Union Risk Assessment Report Draft: Updated risk assessment of 4,4'isopropylidenediphenol (Bisphenol A) (CAS No. 80-05-7; EINECS No. 201-245-8). European Commission, European Chemicals Bureau, Existing Substances. Available from: http://ecb.jrc.ec.europa.eu/esis/inde x.php?PGM=ora

Fang, J. and Alderman, M.H. (2000): Serum uric acid and cardiovascular mortality. The NHANES I epidemiologic follow-up study, 1971-1992. J.Am. Med. Assoc.,2000; 283: 2404-2410.

Gong, Y. and Han, X.D. (2006): Nonlyphenol - induced US and cytotoxicity in testicular sertoli cells. ReprodToxicol., 22:623 630.Grunert, R.R. and Philips, P.H. 1951
Halliwell,B. (1999): Antioxidant defence mechanism: From the beginning to the end (of the beginning). Free Radic Res 31:261-272.

Hamers, T., Kamstra, J.H., Sonneveld, E., Murk, A.J., Kester, M.H. and Andersson, P.L. (2006): In vitro profiling of the endocrine-disrupting potency of brominated flame retardants. ToxicolSci ;92(1):157-73

Hassan, Z., Elobeid, M., Virk, B., Omer, S., ElAmin, M., Daghestani, M. and AlOlaya, E. (2012):Bisphenol A induced hepatotoxicitythrough oxidative stress in rat model. Oxid. Med. Cell. Longev., 2012,192829.

Hasselberg, L., Meier, S. and Svardal, A. (2004): Effects of alkylphenols on redox status in first spawning Atlantic cod (Gadus morhua). Aquat. Toxicol. 69, 95105.

Ho, Y.S., Magnenat, J.L., Gargano, M. and Cao, J. (1998): The nature of antioxidant defense mechanisms: A lesson from transgenic studies.Environ Health Perspect 106:1219-1228.

Huc, L., Lemarie, A., Gueraud, F. and Helies-Toussaint, C. (2012: Low concentrations of bisphenol A induce lipid accumulation mediated by the production of reactive oxygen species in the mitochondria of HepG2 cells. ToxicolIn Vitro 26: 709-717

Hussein, R.M. and Eid, J.I. (2013): Pathological mechanisms of liver injury caused by oral administration of bisphenol A. Life Science,10(1): 663-673.

Kabuto, H., Hasuike, S., Minagawa, N. and Shishibori, T. (2004): 
Effects of bisphenol A on the metabolisms of active oxygen species in mouse tissues. Environ Res, 93:31-35.

Kakkar, P., Das, B. and Viswanathan, P.N. (1984): A modified spectrophotometric assay of superoxide dismutase. Indian J. Biochem.Biophys., 21: 130- 132.

Koc, A., Duru, M., Ciralik, H., Akcan, R.andSogut, S. (2005):"Protective agent, erdosteine, against cisplatininduced hepaticoxidant injury in rats," Molecular and Cellular Biochemistry, vol. 278, no. 1-2, pp. 79-84.

Korkmaz ,A. and Kolankaya, D. (2009): The Protective Effects of Ascorbic Acid against Renal Ischemia-Reperfusion Injury in Male Rats. Ren Fail 31:36-43

Korkmaz, A., Aydogan, M., Kolankaya, D. and Barlas, N. (2009): Vitamin C coadministration augments bisphenolA, nonylphenol, and octylphenol induced oxidative damage on kidney of rats, Environmental Toxicology. PP.325- 337.

Korkmaz, A., Aydogan, M., Kolankaya, D. and Barlas, N. (2010): Influence of vitamin $C$ on bisphenolA, nonylphenol and octyl phenol induced oxidative damages in liver of male rats. Food and Chem. Toxico., 48: 2865- 2871.

Kovacic, P. (2010): "How safe is bisphenol A? Fundamentals of toxicity: metabolism, electron transfer and oxidative stress," MedicalHypotheses, vol. 75, no. 1, pp. 1-4,

Kwon, H.Y., Choi, S.Y., Won, M.H., Kang, T. and Kang, J.H.
(2000).Oxidative modification and inactivation of $\mathrm{Cu}, \mathrm{Zn}$-superoxide dismutase by 2,2'-azobis (2amidinopropane) dihydrochloride. Biochim.Acta., 1543(1):69-76.

Lam, S.H., Haing, M., Zhang, X., Yan, C., Duan, Z., Zhu, L., Ung, C., Mathavan, S., Ong, C. and Cong, Z. (2011): Toxicogenomic and Phenotypic analyses of bisphenol - A early life - exposure toxicity in zebrafish.Plos One, 6, e28273.

Lamberg, S. and Rothstein, R. \{Eds.\} (1978): Laboratory Manual of Histology and Cytology. 2nd ed., A.V.I. Publishing Company, West Port Connecticut, pp: 137-140.

Lee, J.-H., Li, Y.-C. andIp, S.-W. (2008): "The role of $\mathrm{Ca}^{2+}$ in baicalein induced apoptosis in human breast MDA-MB-231 cancer cells through mitochondriaand caspase-3dependentpathway,"Anticancer Research, vol. 28, no. 3, pp. 17011711.

Li ,Y., Xu, C., Yu, C., Xu, L. and Min, M. (2009): Association of serum uric acid level with nonalcoholic fatty liver disease: a cross-sectional study. J. Hepatology. 50: 1029-1034.

Manikkam, M., R. Tracey, C. Guerrero-Bosagna and M.K. Skinner, (2013): Plastics Derived Endocrine Disruptors (BPA, DEHP and DBP) Induce Epigenetic Transgenerational Inheritance of Obesity, Reproductive Disease and Sperm Epimutations. PLoS ONE, 8 (1).

Marmugi,A., Ducheix,S., Lasserre,F., Polizzi, A., Paris,A., Priymenko,N., Bertrand-Michel, J., Pineau, T., Guillou, H., 
Martin, P.G.andMuselli- Lakhal,

L (2011): Low doses of bisphenol

A induce gene expression related to lipid synthesis and trigger triglyceride accumulation in adult mouse liver. Hepatology.vol, Sep 19. In press.

Mathuria, N. and Verma, R.J. (2008): Ameliorative effect of curcumin on aflatoxin-induced toxicity in serum of mice. ActaPol.Pharmaceut. - Drug Res., 65: 339-343.

Maunsbach, A.B. and Afzelius, B.A, (1999): Biomedical Electron Microscopy: Illustrated Methods and Interpretations. Son Diego.Academic Press.

Miyatake, M., Miyagawa, K. , Mizuo, K., Narita, M. and Suzuki ,T. (2006): Dynamic changes in dopaminergic neurotransmission induced by a low concentration of bisphenol-A in neurones and astrocytes.

Neuroendocrinol;18(6):434- 44.

Moon, M.K., Kim, M.J., Jung, I.K., Koo, Y.D., Ann, H.Y., Lee, K.J., Kim, S.H., Yoon, Y.C., Cho, B.J., Park, K.S., Jang, H.C. and Park, Y.J. (2012): Bisphenol A impairs mitochondrial function in the liver at doses below the no observed adverse effect level. Journal of Korean Medical Science 27, 644652.

Mourad, I.M., Khadrawy, Y.A., (2012): The sensitivity of liver, kidney and testis of rats to oxidative stress induced by different doses of Bisphenol-A. International Journal of Life science \&Pharma Research: Vol. 2; 19-28.

Mukherjee, D., Roy, S.G., Bandyopadhyay, A.,
Chattopadhyay, A., Basu, A., Mitra, E., Ghosh, A.K., Reiter, R.J., Bandyopadhyay, D., (2010):Melatonin protects against isoproterenol-induced myocardial injury in the rat: antioxidative mechanisms. Journal of Pineal Research 48, 251-262.

Murmu, S., and Shrivastava, V.K. (2014). Role of Vitamin $\mathrm{C}$ as antidote against Bisphenol A toxicity in kidney of fresh water fish Cirrhinusmrigala (Ham) an international quarterly journal of Environmental Sciences. Vol. VI: 499-503.

Neha, P., Sangat, Ramtej, J. and Verma. (2012): Quercetin ameliorates bisphenol Ainduced toxicity in mice. Acta Poloniae Pharmaceutica- Drug Research, Vol. 69 No. 3. pp. 557- 563.

Ogunleye, R.F.andOmotoso,O.T. (2005): Edible orthopetran and lipidopetran as protein substitutes in the feeding of experimental albino rats. African Journal of Applied Zoology \& Environmental Biology.Vol.7.48-51.

Olea-Herrero, N.1., Arenas, M.I., Muñóz-Moreno, C., Moreno Gómez-Toledano, R., GonzálezSantander, M., Arribas, I. andBosch, R.J. (2014): BisphenolA induces podocytopathy with proteinuria in mice. Journal of Cell Physiol. 229(12):2057- 2066.

Reddy, K.P., Subhani, S.M., Khan, P.A. and Kumar, K.B. (1995): Effect of light and benzyl adenine and dark - treated graving rice (Oryza sativa) leaves - changes in peroxidases activity. Plant Cell Physiol; 26: 987 - 994.

Rietjens,I.M.C.M.,Boersmaa,M.G.,d eHaana,L.,Spenkelinka,B.,Awad 
a,H.M.,Cnubbenb, N.H.P.,van Zandena,J.J.,vander,W.H., Alinka,G.M. and Koemana JH. (2002): the pro-oxidant chemistry of the natural antioxidants vitamin C, vitamin E, carotenoids and flavonoids. Environ

ToxicolPharmacol 11:321-333.

Romero, M., Ortega, A., Izquierdo, A., Lopez-Luna, P. and Bosch, R.J. (2010): Parathyroid hormonerelated protein induces hypertrophy in podocytes via TGF-beta(1) and p27(Kip1): Implications for diabetic nephropathy. Nephrol Dial Transplant 25:2447-2457.

Roy, S., Kalita C.J.andMazumdar, M. (2011): Histopathlogical effects of Bisphenol $A$ on liver of HeteropneustesFossilis (Bloch). An international Quarterly Journal of Environmental Sciences theEcoscan, 1: 187-190.

Sangai, N.P., Verma R.J. andTrivedi, M.H. (2012):Testing the efficacy of quercetin in mitigating bisphenol A toxicity in liver and kidney of mice. Toxicology and Industrial Health, pp: 1-17.

Sayed-Ahmed, M. M., Aleisa, A. M. and Al-Rejaie, S. S. (2010): Thymoquinone attenuates diethylnitrosamine induction ofhepatic carcinogenesis through antioxidant signaling," Oxidative Medicine and Cellular Longevity, vol. 3, no. 4, pp. 254-261.

Snyder, R.W., Maness, S. C., Gaido , K.W., Welsch ,F. and Sumner, S.C. (2000): Metabolism and disposition of bisphenol $A$ in female rats. ToxicolApplPharmacol 168: 225-234.

Sun, H., Xu, L.C., Chen, J.F., Song, L. and Wang, X.R. (2006):Effect of bisphenol tetrachlorobisphenol A and pentachlorophenol on the transcriptional activities of androgen receptor-mediated reporter gene. Food Chem Toxicol;44(11):1916-21.

Tian, X., Takamoto, M., Sugane, K. (2003): Bisphenol A promotes IL-4 production by Th2 cells. Int Arch Allergy Immunol;132(3):240-247.

Vandenberg, L.N., Chahoud, I., Heindel, J.J.,Padmanabhan, V., Paumgartten, F.J. andSchoenfelder, G.(2010). Urinary, circulating, and tissue biomonitoring studies indicate widespread exposure to bisphenol A. Environ. Health Perspect., 118: 1055-1070.

Walaa, M.S., Ahmed, Walaa, A., Moselhy and Nabil, T.M. (2015): Bisphenol A Toxicity in Adult Male Rats: Hematological,Biochemical and Histopathological Approach. Global Veterinaria,14 (2): 228-238.

Wei, X., Ying J., Yuanyuan, L.i., Yanjian, W., Juan, L., Yue, M., Zhenxing, M., Huailong, C., Gengqi, L., Bing, X., Xi, C. and Shunqing, X. (2014): Early-Life Exposure to Bisphenol A Induces Liver Injury in Rats Involvement of Mitochondria Mediated Apoptosis. PLoS One. 9(2): e90443.

Yildiz, N. and Barlas, N. (2013): Hepatic and renal functions in growing male rats after bisphenol A and octylphenol exposure. Human \& Experimental Toxicology, 32: 675-686.

Ziyadeh, F.N. and Wolf, G. (2008). Pathogenesis of the podocytopathy and proteinuria in diabetic glomerulopathy.Curr Diabetes Rev $4: 3945$. 


\section{تأثير فيتامين ج علي سمية مادة البسفينول أ علي الكبا و الكلي في

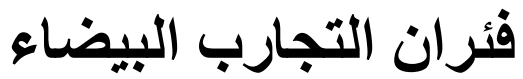

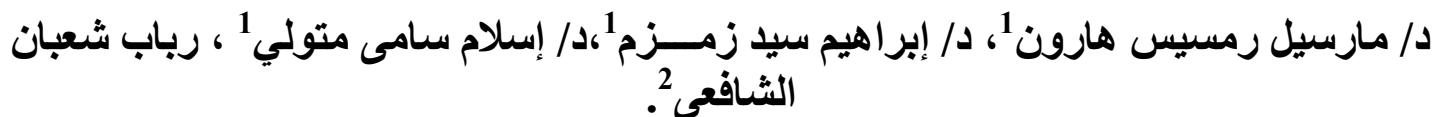
1 قسم الطب الشرعى و السموم الأكلينيكية، كلية الطب، جامعة بنها، مصر ، ${ }^{2}$ مدرس مساعد بقسم الطب

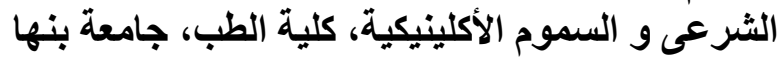

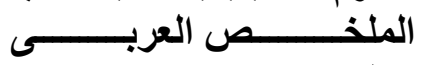

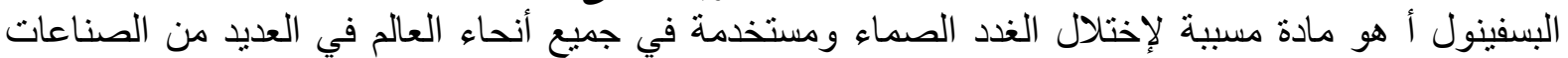

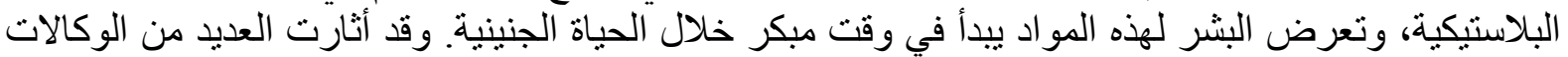

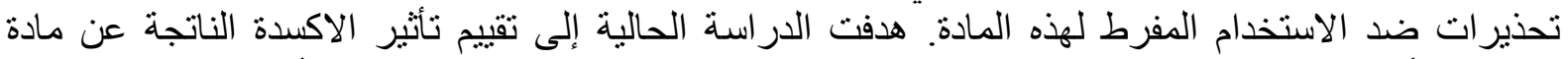

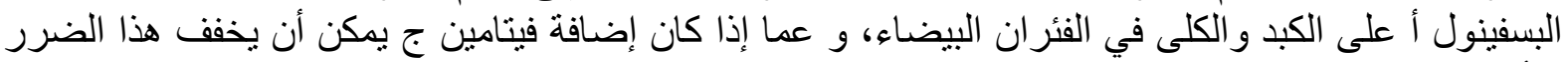

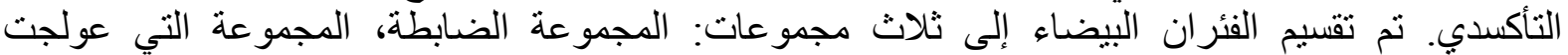

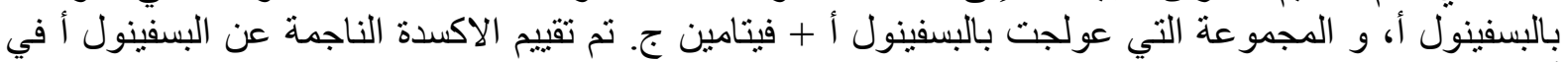

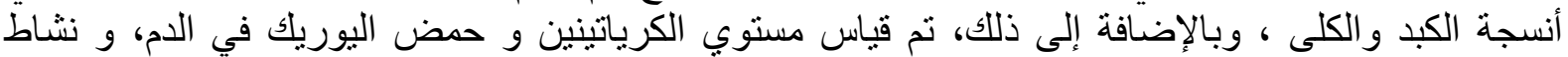

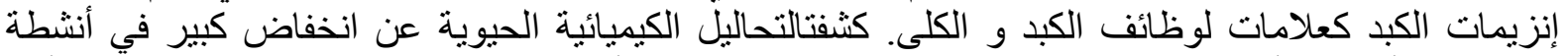

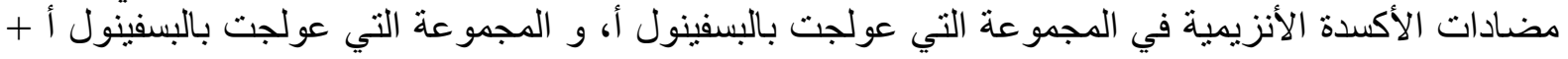

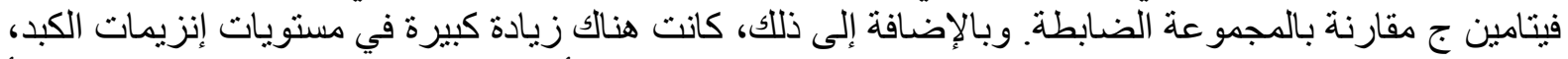

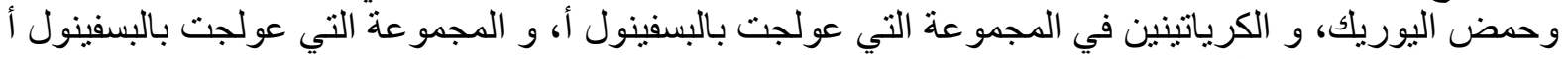

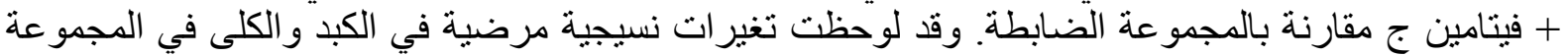

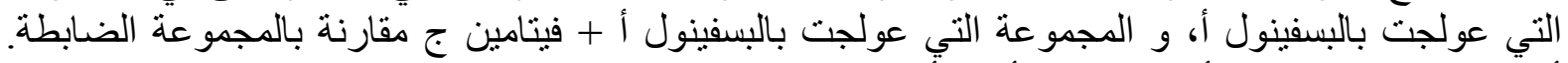

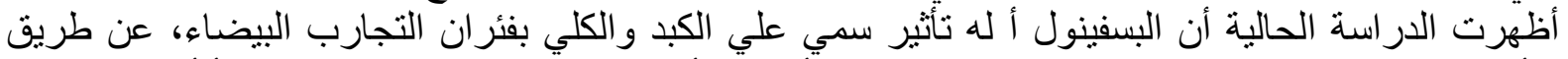

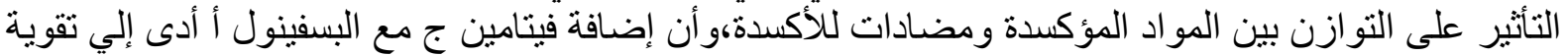

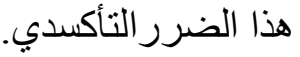

